\title{
OBSERVATIONS ON THE ABSORPTION OF RADIOACTIVE STRONTIUM AND YTTRIUM BY MARINE ALGAE
}

\author{
By G. M. Spooner, M.A. \\ Zoologist at the Plymouth Laboratory
}

(Text-figs. I-IO)

In the autumn of 1948 , when radioactive strontium (in solution) was being used as a source of $\beta$-rays for irradiating Gammarus, some 'tracer' experiments were undertaken to test the degree of uptake, if any, of the 'active'1 strontium by inanimate and living objects, including marine algae. The results obtained with algae have some special points of interest, and have confirmed the belief that the use of radioactive isotopes might become a powerful tool in advancing knowledge of the chemical exchanges between marine organisms and their environment. They are therefore described as far as they have been carried to date.

The work formed part of the investigations supported by the Atomic Energy Research Establishment ${ }^{2}$ of the Ministry of Supply, who supplied the isotopes and lent special equipment, and by whose permission this account is published.

The writer gratefully acknowledges the help given in various ways by Dr J. F. Loutit and Dr G. E. Harrison, of the Radiobiological Research Unit at A.E.R.E., Harwell. Dr Harrison has been relied on for advice on the nuclear-physics aspects of the problems investigated. The pleasantest recollections are entertained of the kindness received from them and from various members of the A.E.R.E. staff during a week's visit to Harwell in December I947.

I am particularly grateful to the Director, Mr F. S. Russell, F.R.S., for having, in the first place, afforded me the opportunity of exploring a new field, and to him and to Dr W. R. G. Atkins, F.R.S., for their constant sympathetic interest.

The work would have been impossible without the active co-operation of Dr H. W. Harvey, F.R.S., who kept me plied with practical suggestions and devised details of technique; and of $\mathrm{Mr} \mathrm{F}$. J. Warren, who effectively main-

1 The terms 'active' and 'activity' used throughout this paper mean 'radioactive' and 'radioactivity'. Though these, as well as the expression 'decay', are well-established terms in the literature of the subject, they are retained in inverted commas for the benefit of readers who are not familiar with this field of research, and to distinguish them from the words used in the normal sense.

2 Hereafter referred to as A.E.R.E.

JOURN. MAR. BIOL. ASSOC. vol. XXVIII, I949 
tained the Geiger-Müller counter in working order. I am deeply grateful to them.

It was from Dr Harvey that the suggestion to investigate the larger algae originally came.

I also have pleasure in thanking Dr Mary Parke for identifications of algae, and for making up samples from the Laboratory cultures of unicellular algae, and $\mathrm{Mr}$ F. A. J. Armstrong for taking responsibility for disposing radioactive waste at sea.

The literature consulted on the general aspects of the subject has been mainly confined to the following books or articles:

Smyth (1945). The official White Paper on the development of atomic energy.

Lea (1946). Actions of Radiations on Living Cells.

Pollard \& Davidson (1942, reprinted 1947). Applied Nuclear Physics.

Seaborg (1944). 'Table of isotopes.'

Hoag, revised by Korff (1948). Electron and Nuclear Physics.

Considerable delay, due to the supply situation, was experienced in securing copies of the last three mentioned.

\section{METHODS}

The radioactive isotopes are here used in the role of so-called 'tracers', that is to say, they are regarded as a specially labelled component of the total amount of the element present. If, for example, interest is focused on the fate of 'active' $\mathrm{Sr}^{89}$, it is not because this isotope has a peculiar chemical behaviour of its own, but because the isotope is a guide to the behaviour of the total strontium present, of which all but a negligible amount is the natural stable element. There is virtually no difference in the chemical behaviour of members of a group sharing the same Atomic Number (isotopes); and if some atoms of a new isotope are added to a previous aggregation of the element, with freedom to move, they distribute themselves at random through the aggregation. If, between its aquatic environment and an organism, the 'activity' due to $\mathrm{Sr}^{89}$ is found partitioned in a ratio of, say, $\mathrm{I}: 3$, it is taken to imply that all the strontium in the system is so distributed. The wording of the title (p. 587) should thus be expanded to ' . . . absorption of strontium and yttrium as demonstrated by changes in concentration of radioactive strontium and yttrium'.

The two essential requisites in this type of investigation are: (i) the radioactive isotope, in solution or in other suitable form; and (ii) a method of measuring the 'activity' of the experimental material, or samples of it. The manipulative technique in the application of the isotope may be very simple; on the other hand, the full analysis of the collated measurements of 'activity', including 'decay' curves of specimens, may involve much labour. This is particularly true, if, as here, more than one 'active' isotope is dealt with in the same experiment. 


\section{The Isotope Mixture}

The isotope was supplied in the form of a weak solution of strontium chloride, of which all the strontium was in the form of its two 'active' isotopes, $\mathrm{Sr}^{89}$ and $\mathrm{Sr}^{90}$. As time passes two stable 'decay' products accumulate, yttrium and zirconium, the latter very slowly. With the loss of an electron ( $\beta$-ray), $\mathrm{Sr}^{89}$ passes direct to stable yttrium, while $\mathrm{Sr}^{90}$ changes first to $\mathrm{Y}^{90}$, which in turn changes to zirconium. The processes are summarized as follows:

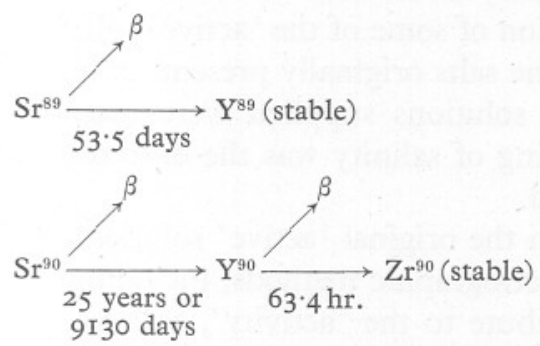

In the above formulae the periods given below the arrows are the 'half-lives' (expectation of time taken for half the original number of atoms to disintegrate, or, otherwise stated, for 'activity' to reduce to one-half). The three nuclear reactions involved proceed at very different rates, and naturally, the greater the rate of 'decay', the greater the 'activity' of the parent element. Thus, although $\mathrm{Sr}^{89}$ and $\mathrm{Sr}^{90}$ may originally be present in equal quantities, the 'activity' of the $\mathrm{Sr}^{90}$ will be far less-only $53.5 / 9 \mathrm{r} 30=0.00586$, that of the $\mathrm{Sr}^{89}$. Clearly, as time passes, the ratio of the quantities of $\mathrm{Sr}^{89}: \mathrm{Sr}^{90}$ steadily drops, and correspondingly the ratio of their 'activities'. Eventually the 'activity' of the $\mathrm{Sr}^{90}$ is of comparable strength to that of the $\mathrm{Sr}^{89}$, and later still accounts for virtually all the surviving 'activity'. But the 'activity' due to the $\mathrm{Sr}^{90}$ is, so to speak, automatically doubled through the presence of its short-lived daughter product, $\mathrm{Y}^{90}$. While the daughter $\mathrm{Y}^{90}$ remains in equilibrium with the parent $\mathrm{Sr}^{90}$, its 'activity' is identical with that of its parent; since the amount of $\mathrm{Y}^{90}$ 'decaying' equals the amount forming, and thus equals the amount of $\mathrm{Sr}^{90}$ 'decaying'. The fraction of the 'activity', in the mixture, due to yttrium may thus be appreciable, although the actual quantity present at any instant immeasurably small.

The presence of the daughter product, $\mathrm{Y}^{90}$, itself a radioactive isotope, makes possible a double investigation in the experiments to be described. The absorption of yttrium can be studied in the same specimens as that of strontium.

A further physical characteristic, of which account has to be taken in making measurements, is the maximum energy of the $\beta$-rays produced by each of the reactions. Fortunately, these are not greatly dissimilar-for the rays from $\mathrm{Sr}^{89}$ the value is given as $\mathrm{I}^{\cdot} 5$, for $\mathrm{Sr}^{90}$ it is 0.65 , and for $\mathrm{Y}^{90}$ it is $2 \cdot 2 \mathrm{mev}$. The last 
have the greatest energy and are therefore the most penetrating. The screening of specimens undergoing measurement will tend to exaggerate the importance of the $\mathrm{Y}^{90}$ component a little.

\section{Chemical Effects of the Isotope Solution}

The actual concentrations of strontium and yttrium in the isotope solution, which was 'carrier-free' (i.e. free from stable strontium, which is mainly $\mathrm{Sr}^{88}$ ), were so negligibly small that the chemical effects can be completely ignored. Thus, addition of some of the 'active' solution to sea water does not alter the balance of the salts originally present, or alter the $\mathrm{pH}$.

Since the original solutions supplied were usually diluted with distilled water, a slight lowering of salinity was the only result. Even this effect can be obviated if desired.

Trace impurities in the original 'active' solutions were recorded as having been detected by spectrographic methods, including $\mathrm{Ca}, \mathrm{Ba}, \mathrm{Al}, \mathrm{Mg}, \mathrm{Fe}, \mathrm{Pb}$. These did not contribute to the 'activity', and were in all respects entirely negligible.

\section{'Decay' and Daughter-product 'Recovery'}

The quantity of a radioactive substance present, after an interval $t$, is given by the well-known logarithmic curve

$$
Q_{t}=Q_{0} \epsilon^{-\lambda t},
$$

where $Q_{0}$ is the quantity at the start, and $\lambda$ the specific 'decay constant' of the substance concerned. But $\lambda=\log _{\epsilon} 2 / H=0.693 / H$, where $H$ is the 'half-life', a constant which is more familiar than $\lambda$. Thus $Q_{t}=Q_{0} \epsilon^{-0 \cdot 693 t / H}$, which simplifies to

$$
Q_{t}=Q_{0} 2^{-t / H} .
$$

This form of the equation is most convenient to use in calculating theoretical 'decay' curves, and will be adopted in this paper. A logarithmic plot gives a straight line.

The measurable 'activity' 'decays' in precisely the same way:

$$
A_{t}=A_{0} 2^{-t / H} \text {. }
$$

Suppose the solution used in an experiment contained at the start a mixture of $\mathrm{Sr}^{89}$ and $\mathrm{Sr}^{90}$, so that the ratio of their respective 'activities' was $x: \mathrm{I}$. There would also be $\mathrm{Y}^{90}$ which had accumulated as a daughter product of $\mathrm{Sr}^{90}$, with an 'activity' ratio of $\mathrm{I}$. The triple ratio is thus $x: \mathrm{I}: \mathrm{I}$.

After an interval of $t$ days, the respective 'activities' have become

$$
x 2^{-t / 53 \cdot 5}: 2^{-t / 9130}: 2^{-t / 9130} \text {. }
$$

For a period of a few months the change in the last two values is negligible for most purposes, so that the values simplify to

$$
x 2^{-t / 53 \cdot 5}: \text { I : I. }
$$


A general 'decay' curve for mixtures of $\mathrm{Sr}^{89}$ and $\mathrm{Sr}^{90}$ has been worked out. For any given mixture a corresponding point on the curve is found, and the predicted subsequent history of the mixture is given by following the curve from that point. ${ }^{1}$ This curve is frequently referred to hereafter as the 'equilibrium decay curve': it is only valid if the $\mathrm{Y}^{90}$ remains in equilibrium with the $\mathrm{Sr}^{90}$.

Under some conditions all, or part, of the yttrium formed may be removed from the solution: for example, it may be adsorbed on objects in contact with the solution. If the yttrium is removed at a constant rate a new equilibrium is established in which the 'activity' of the $\mathrm{Y}^{90}$ is less than that of $\mathrm{Sr}^{90}$.

Supposing that yttrium has been removed, and the mixture then allowed to recover equilibrium - as might happen when a drop is removed from the yttrium-deficient solution and placed on a slide for measurement. If the specimen is measured at intervals it will be observed to increase in 'activity' for a time, for the rate of accumulation of $\mathrm{Y}^{90}$ will at first be greater than the combined 'decay'. If the 'activity' at first is

$$
x: \mathrm{I}: \mathrm{O},
$$

after an interval of $t$ days it becomes

$$
x 2^{-t / 53 \cdot 5}: 2^{-t / 9130}: \frac{9 \mathrm{I} 30}{9 \mathrm{I} 27 \cdot 36}\left(2^{-t / 9130}-2^{-t / 2 \cdot 642}\right) .
$$

The more complex expression for $\mathrm{Y}^{90}$ 'activity' is sufficiently close to $\left(\mathrm{I}-2^{-t / 2 \cdot 642}\right)$ for most practical purposes. Its value increases rather rapidly from zero during the first few days, when the rate of increase of the $\mathrm{Y}^{90}$ is greater than the rate of decrease of all three constituents combined. After a definite interval a maximum is reached. This time is easily calculated by differentiating and equating to zero. This gives

$$
\frac{9130}{9127 \cdot 36} \times \frac{I}{2 \cdot 642} 2^{-t / 2 \cdot 642}=\frac{x}{53 \cdot 5} 2^{-t / 53 \cdot 5}+\left(\frac{I}{9130}+\frac{I}{9127 \cdot 36}\right) 2^{-t / 9130},
$$

or, simplifying for short periods, when the last term on the right can be ignored,

or

$$
\begin{gathered}
\frac{\mathrm{I}}{2 \cdot 642} 2^{-t / 2 \cdot 642}=\frac{x}{53 \cdot 5} 2^{-t / 53 \cdot 5}, \\
t=\mathrm{I} 2 \cdot 062-9 \cdot 2325 \log x .
\end{gathered}
$$

When only part of the yttrium has been lost, and if the activity ratios are at first: $x: \mathrm{I}: y(y$ being $<\mathrm{I})$; then after an interval of $t$ days it becomes

$$
x 2^{-t / 53 \cdot 5}: 2^{-t / 9130}: \frac{9 \mathrm{I} 30}{9 \mathrm{I} 27 \cdot 36} 2^{-t / 9130}+\left[y-\frac{9 \mathrm{I} 30}{9 \mathrm{I} 27 \cdot 36}\right] 2^{-t / 2 \cdot 642}
$$

${ }^{1}$ Since this curve is a compound of two curves, it is not a straight line when plotted logarithmically. 
The 'activity' rises to a maximum when

$$
\frac{\left(\frac{9 \mathrm{I} 30}{9 \mathrm{I} 27 \cdot 36}-y\right) 2^{-t / 2 \cdot 642}}{2 \cdot 642}=\frac{x}{53 \cdot 5} 2^{-t / 53 \cdot 5}+\left(\frac{\mathrm{I}}{9 \mathrm{I} 30}+\frac{\mathrm{I}}{9 \mathrm{I} 27 \cdot 36}\right) 2^{-t / 9130} .
$$

Again, neglecting the last term, and approximating,

or

$$
\begin{gathered}
\frac{(\mathrm{I}-y)}{2 \cdot 642} 2^{-t / 2 \cdot 642}=\frac{x}{53 \cdot 5} 2^{-t / 53 \cdot 5}, \\
t=\mathrm{I} 2 \cdot 062+9 \cdot 2325[\log (\mathrm{I}-y)-\log x] .
\end{gathered}
$$

Equilibrium is said to be attained when the 'activity' curve approximates to the general 'decay' curve, which depends solely on the proportion of $\mathrm{Sr}^{89}$ to $\mathrm{Sr}^{90}$ in the sample-in other words, when the term $2^{-t / 2 \cdot 642}$ in expression (5) has become negligible.

Many of the curves shown in the figures are seen to start with an initial rise before reaching a maximum, and then falling to meet the equilibrium 'decay' curve. This is due, as just explained, to 'yttrium recovery', the specimen being to some degree yttrium-deficient when it was first prepared.

Other curves are seen, by contrast, to start with a steep drop (Figs. 3 and 8) and grade exponentially towards the gently downward slope of the equilibrium 'decay' curve. In these the specimen starts with an excess of $\mathrm{Y}^{90}$, and nearly always contains an object or part of an object which has a special tendency to take up yttrium.

Clearly, by careful estimation of these departures from the equilibrium 'decay' curve, a calculation can be made of the degree to which yttrium had been removed or concentrated. The point at which the curve starts (the initial measurement), and the length of time taken to reach a maximum or attain near equilibrium provide critical data.

\section{Composition of the Solutions Supplied}

Two separate consignments of 'active' solutions have been received and used in experiments. These are referred to, for brevity, as 'the May solution' and 'the September solution'.

The 'May solution', from investigation of its 'decay' rates at various times, is estimated to have had a $\mathrm{Sr}^{89}: \mathrm{Sr}^{90}: \mathrm{Y}^{90}$ ratio of

$$
\begin{aligned}
& 39.449: \text { I }: \text { I on I April I948 } \\
& =9.443: \text { I }: \text { I on } 2 \text { I July } \\
& =2.092: \text { I }: \text { I on I } 5 \text { November. }
\end{aligned}
$$

The 'September solution' was similarly estimated to have given:

9.78: I : I on 23 September 1948

$=2 \cdot 707:$ I $:$ I on midnight 3I December/I January I949

$=\mathrm{I} \cdot 250: \mathrm{I}: \mathrm{I}$ on midnight $\mathrm{I} / 2$ March. 
Several dilutions of these solutions have been made, usually by addition of measured volumes of distilled water to accurately measured $\mathrm{I} \cdot 0$ or $0.5 \mathrm{ml}$. portions of the original solution.

\section{Measurement of 'Activity'}

A Geiger-Müller counter, loaned by A.E.R.E., was used for measuring the 'activity' of prepared specimens. Descriptions of this excellent instrument may be found elsewhere (see Pollard \& Davidson, I942, pp. 26-30; Hoag, I948, pp. 442-52 for the principles of construction), though doubtless much remains to be written on the subject of its occasional vagaries. It is, however, becoming a familiar object in laboratories, and can serve as an instrument of high precision.

The counter-tube was cased in a M.R.C. Castle and provided with a 'quenching' unit, which allows of precise correction for dead time. A Variac voltage control was fitted to the input of the scalar unit to ensure a steadier voltage than is supplied by the Plymouth electricity authority.

Specimens for measurement were mounted on a microscope slide. These were usually $0.05 \mathrm{ml}$. drops of a solution, carefully measured and evaporated on a warm tray. The solutions being 'activated' sea water, or at least brackish water, the evaporated drop consisted of a fine-grained crystalline patch. An optimum rate of evaporation was found which kept the crystals small and the dried patch even. Other mounts, of thin solid objects, such as pieces of the fronds of algae, or aggregates of unicellular algae, were also made. With solid objects the weight of the specimen was determined when necessary.

Of the four positions in which the tray of an M.R.C. Castle can be placed, position $I$, that nearest to the counter-tube window, was used most frequently. In this position the 'efficiency' of the counter proved to be about $10.6 \% .1$ (A count of Ioo per minute was given by $4.2 \times 10^{-10}$ curies in an evaporated drop. See below.)

Measurements are obtained in terms of discharges, converted to impulses, per minute. When accurately calibrated, one recorded discharge in the counter represents one photon or particle absorbed by the counter (photons of X-rays, $\gamma$-rays, or cosmic rays; particles of $\alpha$ - or $\beta$-rays). The counter-tube, however, does not necessarily record all potentially available radiation-that is, particles which traverse it, or photons which have a reasonable probability of giving up their energy to it. With $\beta$-rays, with which alone we are concerned here, the capacity for absorption is quite high. Not all $\beta$-rays which impinge on the counter-tube window, however, are registered, since a fraction are absorbed in the window itself (made of aluminium foil). The conversion of 'counts' per minute into absolute terms, say total $\beta$-rays discharged by the specimen, involves various complications, but for the most part the problem can be ignored, since most of the critical results involve simply computing ratios

${ }^{1}$ In the second position the equivalent efficiency is about $3.65 \%$. 
between different readings. Results are expressed in relative terms, or related to the same arbitrary scale.

Conversion of counter readings into curie units has been made possible by A.E.R.E., who now supply a standardized solution of $\mathrm{P}^{32}$ (giving $\beta$-rays of I $7 \mathrm{meV}$. maximum energy). Specimen drops have been made up of such a solution in the normal manner. To these can be assigned a definite $\mu \mathrm{c}$. value, subject to the correctness of the specification of the standard, the accuracy of the official value for the half-life of $\mathrm{P}^{32}$ (I4.30 days), and within the limits of accuracy of the measured drop. It was found that an evaporated drop of $0.05 \mathrm{ml}$. volume, on a microscope slide resting on a tray in position I of the castle, will give a count of 100 per minute if it contains $4.2 \times 10^{-10}$ curies. This is equivalent to $8.4 \times \mathrm{IO}^{-3} \mu \mathrm{c}$. per ml.

In working the counter the chief necessary precaution has been to guard against minor fluctuations in the rate of counting. All counter-tubes used have exhibited these. Such fluctuations are made possible, apparently, by the fact that some particles entering the counter-tube cause two discharges, and others sometimes fail to cause any. An uneasy balance between these two opposite variations, which tend on the average to cancel each other out, but of which each may on occasion predominate, has to be carefully watched. The best safeguard is the use of a constant source of 'activity', preferably one not subject to measurable 'decay', such as a solid containing uranium. Such a constant source, made of uranium oxide, has been used continuously, and as far as possible the voltage supplied to the counter-tube has been adjusted so that it tended to give a certain constant reading ( 4930 per minute, uncorrected, on tray in position I).

All readings have a standard 'dead time' correction ${ }^{1}$ (see Kamen, I948, p. 82), which has to be added, and a constant 'background' count has to be deducted. At Plymouth, values for the background of reasonable accuracy vary between 8.7 and I0.2 per minute, with 9.5 as a modal value. The latter figure is adopted as the routine correction.

Radioactive 'decay' proceeds essentially at random, though when it is producing impulses at the rate of several thousand a minute this fact is hard to grasp. One result is that variations in counts due to sampling follow the well-known Poisson distribution curve, for which the variance $\left(\sigma^{2}\right)$ is conveniently equal to the mean. Supposing a specimen is measured for $30 \mathrm{~min}$. during which period it has given a count, corrected for dead time, of 3600 . This figure has a variance of $3600(\sigma=60)$, and so the value per minute, i.e. $\mathrm{I} 20$, has a $\sigma$ of $60 / 30=2 \cdot 0$. [Alternatively, $\sigma_{\text {mean }}^{2}=\mathrm{I} 20 / 30=4, \sigma_{\text {mean }}=2$.] In practice a background value of 9.5 per minute will have to be deducted from the empirical count of 120 per minute, giving I IO.5. The corresponding error must not be deducted, but added. For the $\sigma^{2}$ of this corrected mean is $(120+9.5) / 30=4.317$, and $\sigma_{\text {mean }}=2.07$ (or what would normally be the

1 For the particular quenching unit used, the count corrected for 'dead time' was $\mathrm{N} /(\mathrm{I}-0.000,005 \mathrm{~N})$, where $\mathrm{N}$ was the actual count per minute. 
error for a mean of 129.5 ). Similarly, the error for $30-9.5$ is a function of 39.5 , not of 20.5 . It will thus be appreciated that when counts are low, say 60 per minute or less, and the background has to be deducted, the sampling error may be considerable.

Sampling errors have not been computed as a matter of routine, and it is not considered necessary to append them to all readings recorded here. They have, of course, been considered when critical comparison has been required. It is necessary to state that the accuracy of different measurements quoted is variable. Often time could not be spared to keep a specimen in the counter as long as might have been wished. Strongly active specimens are the more accurately measured, requiring less time for a given accuracy, and thus are to be recommended for economy of effort. A count of between 2000 and 6000 per minute should be aimed at, and the specimen given a run of at least $30 \mathrm{~min}$.

Actual sampling errors are probably rather greater than the ideal theoretical, on account of that element of fluctuation in the performance of the countertube for which it is impossible to correct completely.

\section{EXPERIMENTS WITH ALGAE}

In the experiments to be described, of which the one now related in detail was the first, the technique was extremely simple. Sea water was 'activated' by the addition of a small volume of an 'active' solution. A measured volume was put into each of two or more similar glass vessels, usually boiling tubes. One vessel was kept as control, while into the other, or others, was placed a piece of healthy alga frond. The wet weight of the piece of frond, which varied from I to $5 \mathrm{~g}$., was determined at some stage, usually after the water had been sampled. The mouths of the vessels were covered with a glass plate, or stoppered with cotton-wool plugs. They were stood near an artificial daylight source which was kept continuously lit. After an interval, varying between 2 and 5 days, the water in the vessel was tested by the drawing off of one or two measured drops. These were placed on a slide, evaporated, as described above (p. 593) and presented to the counter. The remainder of the experiment consisted in the inyestigation of changes in the 'activity' of these evaporated drops. Sometimes a second or third test was made a day or two later. Details of procedure varied on different occasions, and these will be mentioned as the account proceeds. Small improvements were continually being made, particularly in the accuracy with which the specimen drop was measured and mounted.

The standard quantity taken for each drop was 0.05 c.c., or, at first, an approximation to this. I am much indebted to Dr Harvey for adapting a O.I c.c. pipette in a simple but effective way, so that it could be manipulated accurately by hand. The liquid could be steadied and finally levelled by 
a screw adjustment; care being taken that the glass surface remained clean, the accuracy with which the drop was ultimately measured kept within the limits of $\mathrm{I} \%$ either way. In the first experiment, however, there were possibilities of a considerably greater error.

The measured drop is placed in the centre of a glass slide and allowed to evaporate. The exact shape of the drop is not important, provided the area keeps within that of the window of the counter, i.e. it must not be allowed to attenuate too much in any direction. It is well for the evaporation to take place fairly quickly, say in IO or I5 min., when the crystals of sea salt will be small. The presence of large crystals may increase the self-absorption of the specimen and give somewhat low readings. The slides should therefore be placed on a warm tray, or over a weak bunsen flame. They should be stored in a place where deliquescence in a saturated atmosphere does not occur.

For measuring the 'activity' of the specimen, the slide is placed in the chamber of the counter so that the specimen (evaporated drop) is in an exactly defined position. It is necessary, of course, that all the microscope slides used should be of the same thickness, otherwise variations, small, but important, will arise in the distance of the specimen from the window.

As soon as a specimen is prepared its 'activity' is measured, and further measurements are made at intervals subsequently. From the nature of the 'decay' characteristics of the specimen and the relation between it and the control specimen, the degree of absorption of the 'active' ions by the weed can be accurately determined. It is not necessary to examine the weed itself further, but valuable supplementary or corroborative data can be obtained by mounting a fragment of the alga, well washed, and investigating the 'dzcay' characteristics of any 'activity' it may have absorbed.

The method of analysing and interpreting the 'decay' characteristics of specimen drops is best explained when the results of an actual experiment have been given.

\section{An Experiment with Fucus serratus and Rhodymenia palmata}

In the first experiment, set out on 20 October I948, four boiling tubes were taken and into each $25 \mathrm{ml}$. of sea water were measured, and to each $0.5 \mathrm{ml}$. of an 'active' solution added. [The 'active' solution was the May solution diluted $\times$ II4.] Into one tube $(P)$ a piece of Rhodymenia palmata Grev. frond, $\mathrm{I} \cdot 4 \mathrm{~g}$. in weight, was added, and the second tube $(Q)$ kept it as control. Into a third tube $(R)$ a piece of Fucus serratus L., I·2 g. in weight, was added, and the remaining tube $(S)$ kept with it as control.

It may be noticed that the control solutions are not strictly identical with those of the alga-containing tubes, since the 'active' $0.5 \mathrm{ml}$. was added to each independently, and each tube was liable to a different error in the estimation 
of the $0.5 \mathrm{ml}$. added to it. Tubes $Q$ and $S$ were therefore 'similarly treated' as tubes $P$ and $R$.

The Rhodymenia tube $(P)$ was sampled 3 days later, on 23 October, together with its control $(Q)$, and again on 27 October. Two drops were taken in each sampling $(P$ i and $P$ ii on 23 October; $P$ iii and $P$ iv on 27 October; $Q$ i and $Q$ ii on 23 October). The Fucus tube $(R)$, with its control $(S)$, was sampled on 25 October (drops $R \mathrm{i}, R \mathrm{ii}$ and $S \mathrm{i}, S \mathrm{ii})$, and again on 27 October ( $R$ iii and Riv).

In working out the results of 'activity' measurements, the mean of each pair of drops is taken. Thus $\frac{1}{2}(P \mathrm{i}+P \mathrm{ii})=P a ; \frac{1}{2}(P \mathrm{iii}+P \mathrm{iv})=P b ; \frac{1}{2}(Q \mathrm{i}+Q \mathrm{ii})=Q$, and so on. The 'activity' curves of the various specimens are given in Fig. I (Rhodymenia) and Fig. 2 (Fucus serratus).

A glance at the $P$ and $R$ curves, the positions of which would be widely separated were they placed on the same graph, shows at once that the two algae have given entirely different results. Before, however, this difference is analysed, it is necessary to consider each graph separately, and to be clear how each alga-containing tube differs from its control.

Taking tube $P$ first-it is seen that on the day the sampling was made (23 October) the water in $P$ shows appreciably reduced 'activity' as compared with $Q$, though not excessively less (actually 8I \%). During subsequent days there is some increase in the 'activity' of the control specimen, which reaches a maximum about 27 October, after which it begins to show the expected 'decay'; but there is still greater increase in the 'activity' of the specimen of alga-treated water, as shown by the steep rise in the curve $P$ (actually it is $\mathrm{Pa}$ which is plotted), which does not reach a maximum before about I November. The difference between $P$ and $Q$ steadily reduces until the two values are within $5 \%$, or less, of each other, the final mean ratio of $P / Q$ being $96 \cdot 05 \%$.

As explained above, an increase in the 'activity' of a specimen shows that, when it was prepared, it was deficient in yttrium. The daughter product, $\mathrm{Y}^{90}$, has been wholly or partially removed and is below equilibrium value. In the specimen itself, the amount of $\mathrm{Y}^{90}$ will gradually be restored to equilibrium value by the decay of $\mathrm{Sr}^{90}$. The rate at which this occurs can be calculated as precisely as the accuracy of the values of the 'decay'-constants of $\mathrm{Sr}^{90}$ and $\mathrm{Y}^{90}$ permit. The greater the deficiency of yttrium, the longer is the period of 'recovery' before a maximum 'activity' is attained, and before the eventual establishment of equilibrium, when the 'decay' follows the theoretical curve determined from the ratio of $\mathrm{Sr}^{89}$ to $\mathrm{Sr}^{90}$ in the mixture.

The initial loss of 'activity' due to the removal of $\mathrm{Y}^{90}$ cannot exceed a certain value at a given moment, determined by the proportion of $\mathrm{Y}^{90}$ ' activity out of the total, itself in turn determined by the proportion of its parent $\mathrm{Sr}^{90}$. Once the 'activity' ratio of $\mathrm{Sr}^{89}: \mathrm{Sr}^{90}$ has been determined for a particular hour, the expected fraction of 'activity' due to $\mathrm{Y}^{90}$ can be worked out for any 


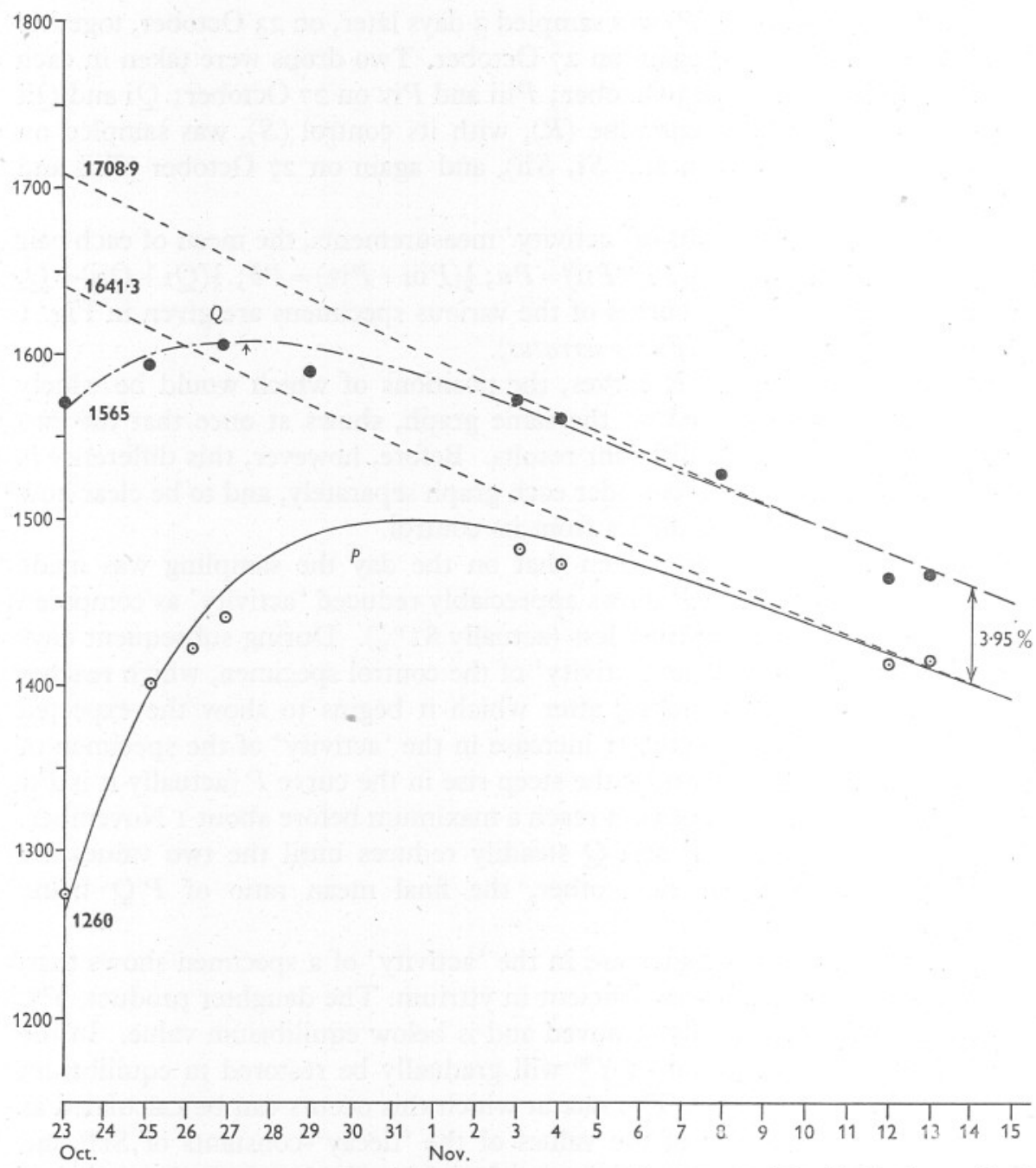

Fig. I. 'Decay' characteristics of a specimen of 'activated' sea water $(P)$ which had contained a piece of Rhodymenia frond; compared with a control specimen of 'activated' sea water $(Q)$. Tube $P$ had held $\mathrm{I} \cdot 4 \mathrm{~g}$. of alga in $25.5 \mathrm{ml}$. of sea water. Curves have been fitted to the two series of points on the assumption that the initial rise is due to recovery of an initial deficiency of $\mathrm{Y}^{90}$. The close-pecked lines represent the two equilibrium 'decay' curves, to which the curves $P$ and $Q$ respectively tend. Activity in arbitrary units. The heavy numerals represent the estimated values of each of the curves at the isolation of the specimens on 23 October. 


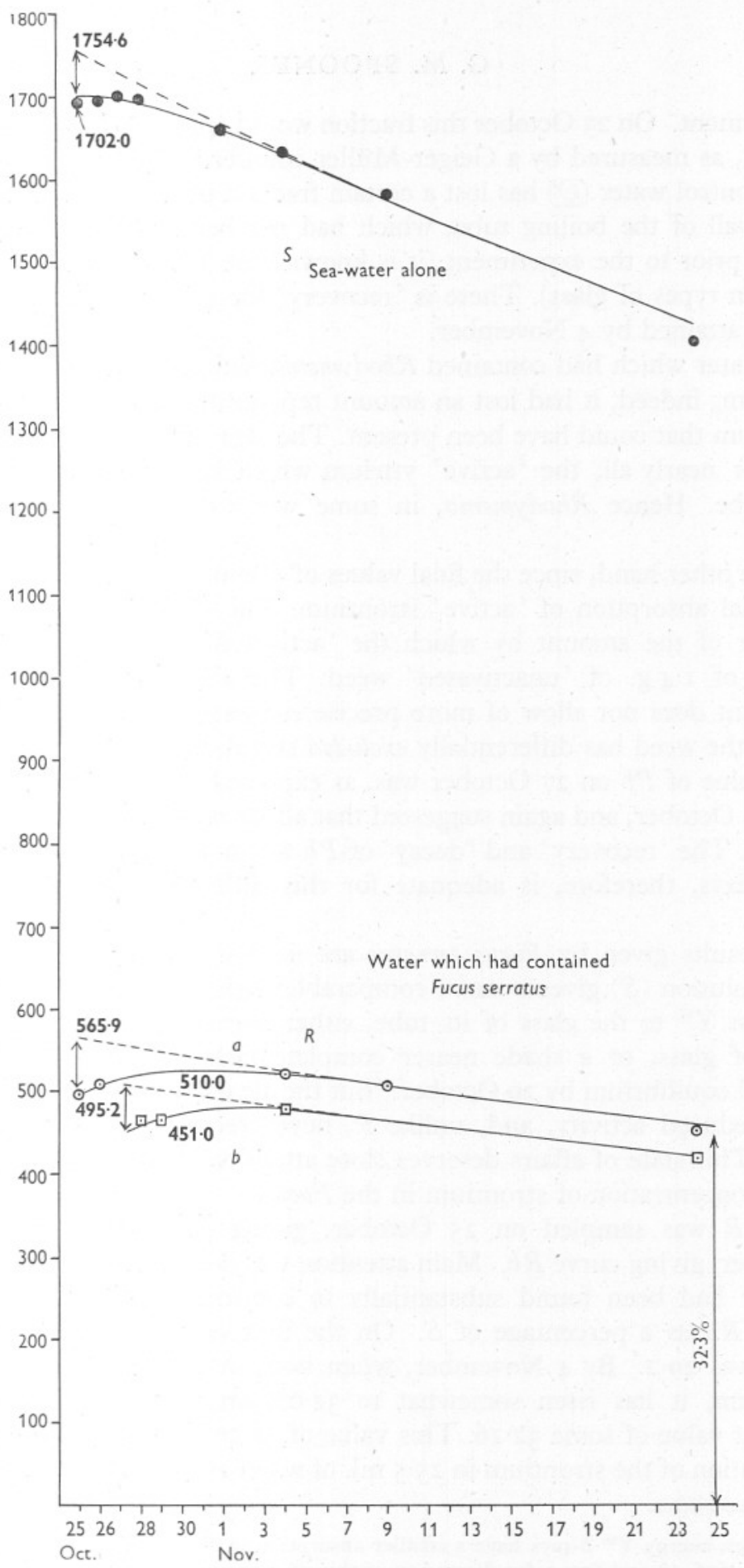

Fig. 2. Curves showing 'decay' characteristics of sea water $(R)$ which had contained a piece of Fucus serratus frond, compared with a control specimen $(S)$. Tube $R$ had held $\mathrm{I} \cdot 2 \mathrm{~g}$. of Fucus serratus in $25.5 \mathrm{ml}$. of sea water, and two specimens ( $a$ and $b$ ) were examined from it. The lines with arrows on the left indicate the extent of the initial yttrium deficiency. Other particulars as in Fig. I. 
other moment. On 23 October this fraction would appear to have been $20 \cdot 7 \%$, or $22.5 \%$ as measured by a Geiger-Müller counter. ${ }^{1}$

The control water $(Q)$ has lost a certain fraction of $Y^{90}$, no doubt adsorbed on the wall of the boiling tube, which had not been subjected to stringent cleaning prior to the experiment (it is known that $\mathrm{Y}$ is liable to be adsorbed on certain types of glass). There is 'recovery' for 4 days, and equilibrium is virtually attained by 4 November.

The water which had contained Rhodymenia had lost considerably more of its yttrium; indeed, it had lost an amount representing all, or very nearly all, the yttrium that could have been present. The alga must therefore have taken up all, or nearly all, the 'active' yttrium which had not gone on the glass of its tube. Hence Rhodymenia, in some way, ${ }^{2}$ differentially concentrates yttrium.

On the other hand, since the final values of $P$ and $Q$ are so close, there is no differential absorption of 'active' strontium. The $4 \%$ or so reduction is of the order of the amount by which the 'activated' water is diluted by the addition of $\mathrm{I} \cdot 4 \mathrm{~g}$. of 'unactivated' weed. The accuracy of this particular experiment does not allow of more precise estimates, and it can not be said whether the weed has differentially excluded strontium.

The value of $\mathrm{Pb}$ on 27 October was, as expected, slightly less than that of $P a$ on 23 October, and again suggested that all, or nearly all, the $\mathrm{Y}^{90}$ had been taken up. The 'recovery' and 'decay' of $P b$ was not studied.

Two days, therefore, is adequate for this differential absorption of $\mathrm{Y}^{90}$ to occur.

The results given by Fucus serratus are in strong contrast (Fig. 2). The control solution $(S)$ gives a curve comparable with $Q$, except that it had lost rather less $\mathrm{Y}^{90}$ to the glass of its tube, either because this was of a different quality of glass, or a shade nearer complete cleanliness. It had virtually recovered equilibrium by 29 October. But the alga-treated solution $(R)$ shows greatly reduced activity, and, unlike $P$, never recovers to the level of the control. This state of affairs deserves close attention, since it points to a substantial concentration of strontium in the Fucus.

Tube $R$ was sampled on 25 October, giving curve $R a$, and again on 27 October, giving curve $R b$. Main attention was devoted to the former when the other had been found substantially to confirm it. It is instructive to consider $R a$ as a percentage of $S$. On the first day, 25 October, this percentage was $29 \cdot 2$. By 4 November, when both samples had nearly attained equilibrium, it has risen somewhat to $32 \cdot 02$, and subsequently settles to a constant value of some $32 \cdot 26$. This value of $32 \cdot 26 \%$ represents the drop in concentration of the strontium in $25.5 \mathrm{ml}$. of water as a result of adding $\mathrm{I} \cdot 20 \mathrm{~g}$. of Fucus serratus.

1 The high energy $\mathrm{Y}^{90} \beta$-rays have a smaller absorption in the window of the counter.

2 See pp. 616-18 and 620-3 for discussion of this phenomenon. 
Thus, adding $\mathrm{I} \cdot 20 \mathrm{~g}$. of Fucus was equivalent to diluting with

$$
\frac{25.5}{0.3226}-25.5=\frac{25.5 \times 0.6774}{0.3226}=53.55 \mathrm{ml} .=55.0 \mathrm{~g} . \text { of sea water, }
$$

or $55 \cdot 0 / \mathrm{r} \cdot 20=45 \cdot 8$ times as much by weight.

The slight rise in 'activity' apparent during the first few days in both the $R a$ and $R b$ specimens makes it clear that the water was even more deficient in yttrium than deficient in strontium. It is easy to calculate that only about $46 \%$ of the expected amount (i.e. of that in equilibrium with the Sr present) remains in the water.

To sum up at this stage, it appears from deficiencies in the sea-water medium that the Rhodymenia has absorbed nearly all the available 'active' $y$ ttrium, but no strontium, whereas the Fucus serratus has taken up part of the yttrium and a good deal of strontium as well. These deductions can be tested by direct observations on the weed itself, as will now be discussed.

A rectangular fragment of the Rhodymenia frond, which was found to have a wet weight of $0.012 \mathrm{~g}$., was placed on a microscope slide and treated as an ordinary specimen. It had first been well rinsed in distilled water, and after mounting it had frequently been moistened with distilled water to keep it something approaching its original shape. The first counter reading, on 5 November, was 4784 per minute (Fig. 3, curve $P$ ). 'Decay', however, was rapid, and it was soon clear, after a few readings at regular intervals, that the rate of 'decay' was close to that of pure $\mathrm{Y}^{90}$ - that is with half-life between 60 and $70 \mathrm{hr}$., or tenth-life of just under 9 days. In Io days (I5 November), indeed, the reading had fallen to 398 per minute. After this the rate of 'decay' gradually eased, until, in early December, it had nearly attained the slow rate of a strontium mixture in equilibrium. By Io December, when excess $\mathrm{Y}^{90}$ must have practically disappeared, a count of 42.5 per minute remained, due to strontium (including the $\mathrm{Y}^{90}$ in equilibrium with it). The final analysis, given in Table I, shows that, on 5 November there was (in arbitrary units of 'activity'):

$4729 \cdot 7$ due to excess $\mathrm{Y}^{90}$.

$53^{\circ} 9$ due to the $\mathrm{Sr}$ mixture, including the $\mathrm{Y}^{90}$ in equilibrium with it.

$=4743^{\cdot} \mathrm{I}$ due to $\mathrm{Y}^{90}, 40 \cdot 5$ due to $\mathrm{Sr}^{89}+\mathrm{Sr}^{90}$.

In other words, the Rhodymenia had taken up a very appreciable amount of 'activity', of which more than $99 \%$ is due to yttrium. Without pressing the significance of the actual figures too far, it is easy to see that the weed had not only concentrated available yttrium very heavily, but had, by contrast, taken up very decidedly less strontium than might have gone into it by free interchange. It may be said to have 'differentially' excluded strontium. The conclusions reached before are thus confirmed and amplified.

A piece of Fucus serratus, similarly treated (Fig. 3, curve $R$ ), clearly behaved 
quite differently. This specimen, however, was not so satisfactory for prolonged study: after a week or so it had dried too far and become strongly curled at the edges. Though it was cut into pieces which could lie together more or less flattened, the original shape could never be restored, and exact results could no longer be expected from it. However, during the first week

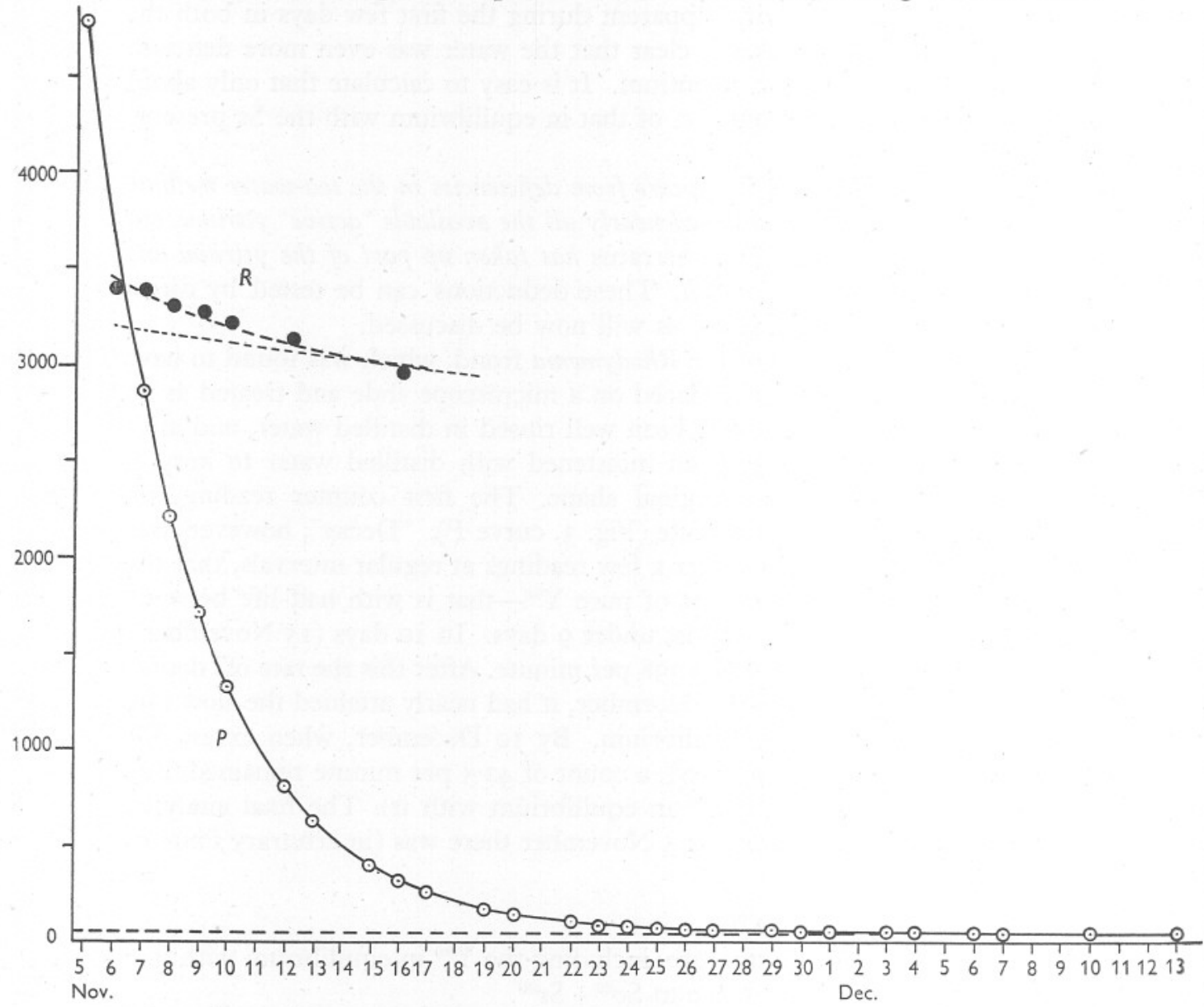

Fig. 3. 'Decay' curves of specimens of alga which had been placed in 'activated' sea water$P$, Rhodymenia falcata; $R$, Fucus serratus. These corroborate the conclusions derived from the study of Figs. I and 2. $P$ is seen to have acquired activity which is due almost entirely to $\mathrm{Y}^{90}$. The activity of $R$ is mainly due to 'active' $\mathrm{Sr}$ mixture, but it has a little excess $\mathrm{Y}^{90}$. The units of the two curves cannot be directly compared.

or so the rate of 'decay' shows two things clearly: (i) the 'activity' must have been mainly derived from strontium, but (ii) it started with an appreciable excess $^{1}$ of $\mathrm{Y}^{90}$, the 'decay' of which is apparent during the first few days.

${ }^{1}$ I.e. excess over the equilibrium value. 
About 3208 of the original count of 3442 (on 6 November) seems to have been due to the strontium equilibrium mixture and 234 to excess $\mathrm{Y}^{90}$. The partial deficiency of $\mathrm{Y}^{90}$ in the water has thus a counterpart of excess in the weed. Again there is corroboration of the conclusions derived from the first method.

\section{Table I. 'Decay' of 'Activated' Rhodymenia Frond (Specimen $P$ )}

'Activity' (in arbitrary units) of a specimen mounted on 5 November and re-measured at noon on various subsequent days.

\begin{tabular}{|c|c|c|c|}
\hline & $\begin{array}{c}\text { (I) } \\
\text { Total } \\
\text { 'activity' }\end{array}$ & $\begin{array}{l}\text { Part due to } \\
\text { Sr equilibrium } \\
\text { mixture }\end{array}$ & $\begin{array}{l}\text { (3) } \\
\text { Part due to } \\
\text { excess } \mathrm{Y}^{90}\end{array}$ \\
\hline${ }_{6}^{5}$ Nov. & $\begin{array}{l}4783 \cdot 6 \\
3630 \cdot 2\end{array}$ & $\begin{array}{l}53.9 \\
53.5\end{array}$ & $\begin{array}{l}4730 \\
3577\end{array}$ \\
\hline 7 & $2869 \cdot 0$ & $53 \cdot 2$ & 2816 \\
\hline 8 & 2209.0 & $52 \cdot 8$ & 2156 \\
\hline 9 & 1713.2 & 52.4 & $166 \mathrm{I}$ \\
\hline Io & I 328.8 & $52 \cdot I$ & I 277 \\
\hline I 2 & 816.9 & $5 I \cdot 4$ & 766.5 \\
\hline I3 & 633.5 & $5 \mathrm{I} \cdot 0$ & 582.5 \\
\hline 15 & $398 \cdot I$ & 50.4 & $347 \cdot 7$ \\
\hline I6 & 313.4 & $50 \cdot 0$ & 263.4 \\
\hline I7 & $255 \cdot \mathrm{I}$ & $49 \cdot 7$ & $205 \cdot 4$ \\
\hline I9 & I $70 \cdot 8$ & $49 \cdot \mathrm{I}$ & $\mathrm{I} 2 \mathrm{I} \cdot 7$ \\
\hline 20 & 143.0 & $48 \cdot 7$ & $94: 3$ \\
\hline 22 & IO2.8 & $48 \cdot I$ & 54.7 \\
\hline 24 & $79 \cdot 5$ & $47 \cdot 5$ & $32 \cdot 0$ \\
\hline 25 & $76 \cdot 0$ & $47 \cdot 2$ & $28 \cdot 8$ \\
\hline 26 & $66 \cdot 25$ & $47 \cdot 93$ & I9.3 \\
\hline 27 & $6 I \cdot 06$ & $46 \cdot 64$ & 14.4 \\
\hline 29 & $53 \cdot 22$ & $46 \cdot 08$ & $7 \cdot I$ \\
\hline 30 & 55.65 & $45 \cdot 80$ & $9 \cdot 8$ \\
\hline I Dec. & $49 \cdot 23$ & $45 \cdot 53$ & $3 \cdot 7$ \\
\hline 3 & $49 \cdot 3^{8}$ & 44.99 & $4 \cdot 4$ \\
\hline 4 & $46 \cdot 3 I$ & $44 \cdot 73$ & $I \cdot 6$ \\
\hline 6 & $45 \cdot 4 \mathrm{I}$ & $44 \cdot 21$ & $I \cdot 2$ \\
\hline 7 & 44.03 & 43.96 & 一 \\
\hline Io & $42 \cdot 39$ & $43 \cdot 22$ & - \\
\hline I3 & $40 \cdot 60$ & $42 \cdot 5 \mathrm{I}$ & - \\
\hline 20 & 39.50 & $40 \cdot 95$ & - \\
\hline
\end{tabular}

Notes. Column (I): as measured. Column (2): smoothed value. Column (3): column (I) less (2). Errors became high towards the foot of column (3). The values in column (2) are derived, knowing the decay characteristics of the 'active' solution used, to give the best fit in two respects - (i) to account for all measured 'activity' from about ro December onwards, so that they represent a smoothed curve for column (I) after that date; and (ii) to make the logarithm of column (3) to plot as a straight line.

\section{Confirmatory Experiments}

Two further tests were made with pieces of $F$. serratus (Exps. $T$ and $V$ ), of which the results essentially confirm the foregoing.

(i) Aliquot parts of $50 \mathrm{ml}$. sea water, activated with I ml. of an 'active' solution on 27 October, were placed in tubes $T$ and $U$. In tube $T$ was then placed a piece of $F$. serratus frond $\mathrm{I} \cdot 05 \mathrm{~g}$. in weight, and $U$ kept as control. Both tubes were sampled 2 days later. The 'decay' curves are given in Fig. 4, 


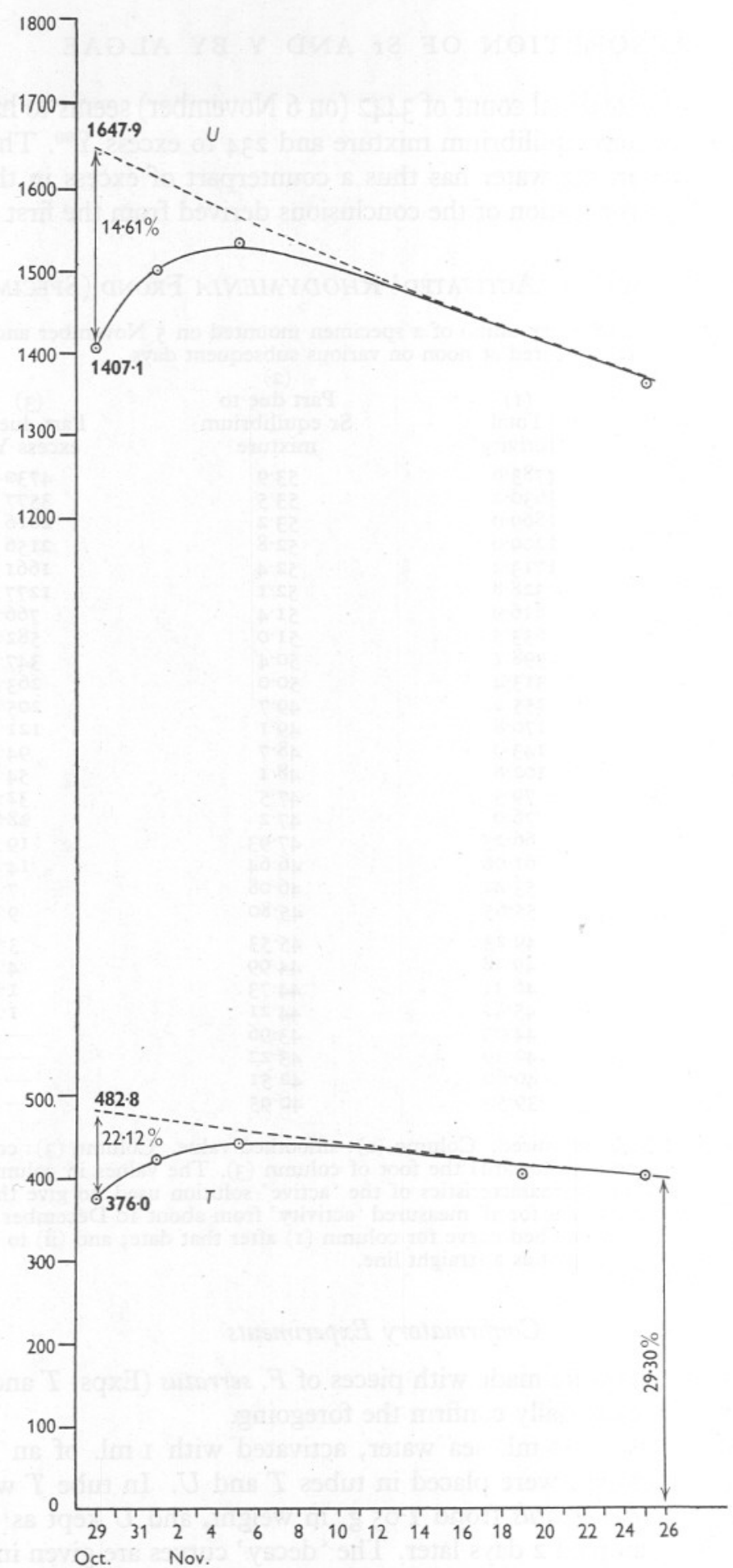

Fig. 4. 'Decay' curves of specimens of 'activated' sea water, as in Fig. 2. T, water which had contained a piece of Fucus serratus (1.05 g. in $25.5 \mathrm{ml}$. of sea water). U, control. 'Activity' in arbitrary units. 
from which a close resemblance to Fig. 2 at once comes to notice. The value of the sample from $T$ is at first $26.72 \%$ that of $U$ and increases to $29.65 \%$. Thus, reasoning as before, $\mathrm{I} \cdot 05 \mathrm{~g}$. of weed is equivalent to

$$
\frac{25.5 \times 0.7035}{0.2965}=60.5 \mathrm{ml} \text {. of sea water. }
$$

This is a weight of $62.14 \mathrm{~g}$. The degree of concentration of the strontium is thus as much as 59 times.

This experiment thus suggests an even higher concentration of strontium in the weed, but the failure, in this particular experiment, to measure the divided volumes exactly may have introduced an error of 3 or possibly $5 \%$. There is partial yttrium deficiency in both $T$ and $U$, as was found in Exp. $R$.

(ii) On 29 October another similar experiment was set up. This time the division of the 'activated' sea water was precise. The 'activity' of the water was less than before. To $50 \mathrm{ml}$. of 'outside' sea water was added $0.5 \mathrm{ml}$. of 'active solution $D$ ' $(D=$ the September solution diluted $\times 560)$. Into tube $V$ was placed $2.9 \mathrm{~g}$. of $F$. serratus, and tube $W$ was kept as control. The tubes had been treated with strong cleaning fluid and, probably as a result, hardly any yttrium was taken up by the control. Specimens were taken on 3 November, 5 days later. The 'decay' curves are given in Fig. 5. The final percentage of the 'activity' of the water in $V$ compared with $W$ is $18.80 \%$. Thus $2.9 \mathrm{~g}$. of weed is equivalent to

$$
\frac{25 \cdot 25 \times 0.8 \mathrm{I} 2}{0 . \mathrm{I} 88}=\mathrm{I09} \cdot \mathrm{I} \mathrm{ml} .=\mathrm{II} 2.0 \mathrm{~g} . \text { of sea water, }
$$

or 38.6 times the weight of the weed.

Rhodymenia was again tested on a later occasion (3 December). The 'activated' sea water used was that which had served as control for the previous experiment, i.e. from tube $Q$. Of this $20 \mathrm{ml}$. were drawn off and placed in tube $L$, the remaining $4 \mathrm{ml}$., or so, were kept as control. In tube $L$ was placed $0.78 \mathrm{~g}$. of Rhodymenia frond. The water was sampled on 8 December. The 'activity' curves, shown in Fig. 6, are similar to those in Fig. I, the alga-treated water showing heavy yttrium deficiency but no strontium deficiency. As the solution is 6 weeks 'staler', there will be rather more yttrium (relatively) present at the start; and, since the ratio $\mathrm{Sr}^{89}: \mathrm{Sr}^{90}$ is now lower by nearly half, the 'decay' of the equilibrium mixture is decidedly slower.

The 'recovery' of the alga-treated water is so complete, as to suggest that the alga had not taken up any 'active' strontium at all. At least it seems that the weed had much less diluting effect than an equivalent weight of water. But again it has taken up almost all available yttrium (probably less had gone on the glass in the clean boiling tube containing the $20 \mathrm{ml}$. than in the control tube, the original tube $Q$, which had not been in cleaning fluid and had been 


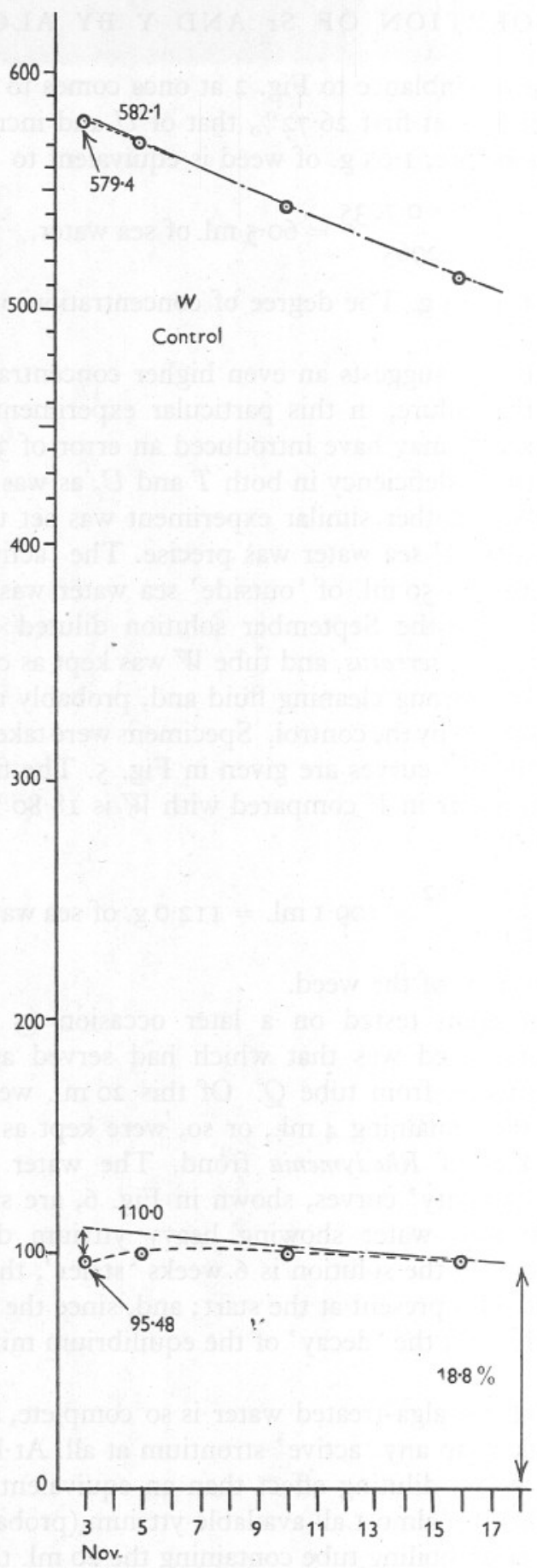

Fig. 5. Similar 'decay' curves as in Figs. 2 and 4. $V$, water which had contained Fucus serratus $(2.90 \mathrm{~g}$. in $25.25 \mathrm{ml}$. of sea water). W, control. 

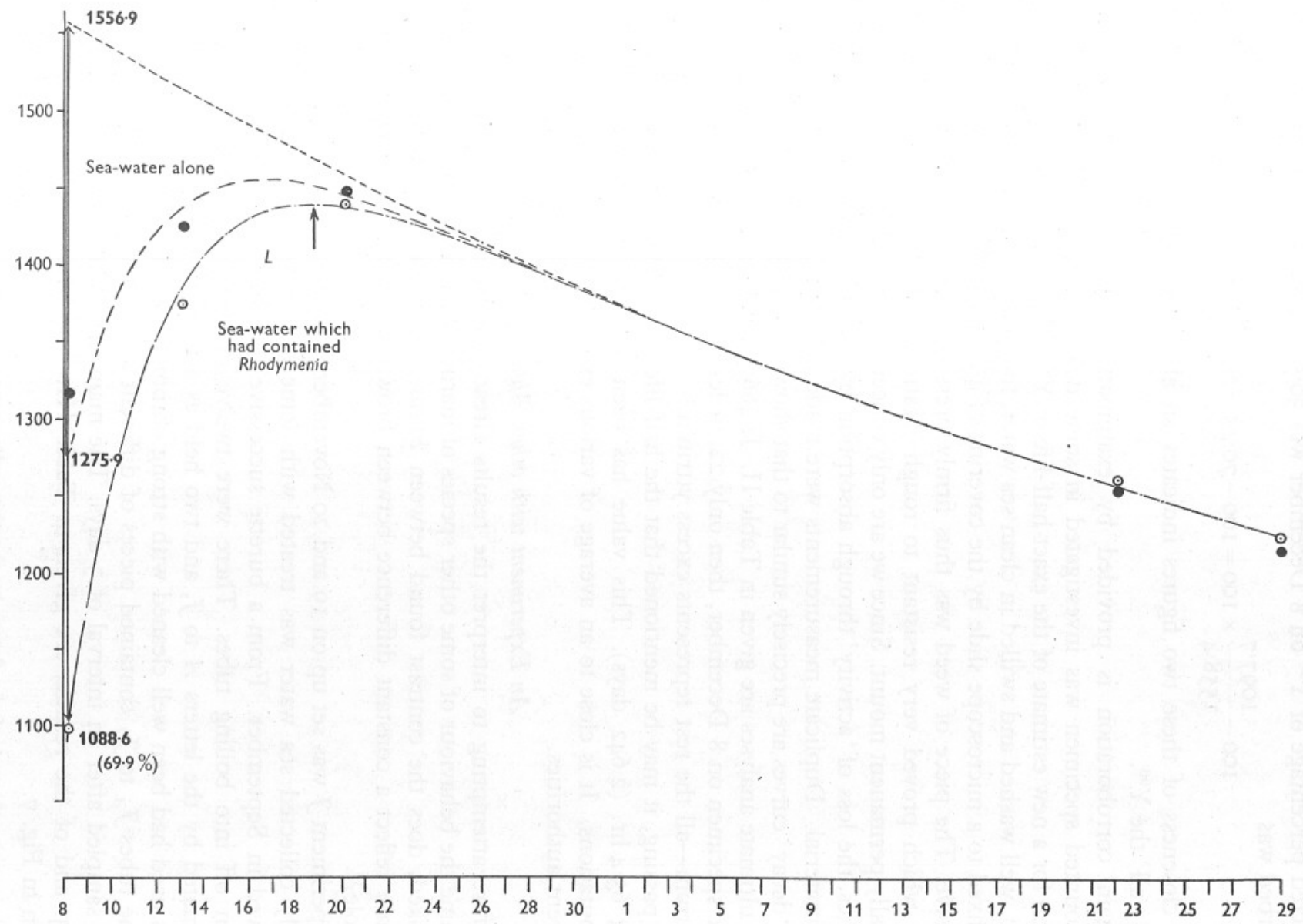
Dec.

Jan

Fig. 6. 'Decay' curve $(L)$ of specimen of activated sea water in which a piece of Rhodymenia frond ( $0.78 \mathrm{~g}$. in $20 \mathrm{ml}$. of sea water) had been placed, as in experiment shown in Fig. I. $\odot-\odot$, specimen of alga-treated water. type of vessel). -----, 'decay' curve of equilibrium mixture. 'Activity' in arbitrary units. Other particulars as before. 
standing with sea water for some 6 weeks). Calculation shows that the expected percentage of $\mathrm{Y}^{90}$ on 8 December was $30.59 \%$, and the percentage absorbed was

$$
100-\frac{\mathrm{I097} 7}{\mathrm{I} 558 \cdot 4} \times 100=100-70 \cdot 45=29 \cdot 55 \% \text {. }
$$

The closeness of these two figures indicates an absorption of all or 'very nearly all' the $\mathrm{Y}^{90}$.

Again corroboration is provided by examination of the weed itself. A mounted specimen was investigated in some detail, being one that was chosen for a new estimate of the exact half-life of $\mathrm{Y}^{90}$. The damp fragment of frond, well washed and swilled in clean sea water, followed by distilled water, was fixed to a microscope slide by the covering of a broad strip of cellophane adhesive. The piece of weed was thus firmly pressed down by a protective layer which proved very resistant to rough treatment. It has provided a virtually permanent mount. Since we are only concerned with 'decay' characteristics, the loss of 'activity' through absorption by the cellophane covering is immaterial. Duplicate measurements were made in two counter positions. The 'decay' curves are precisely similar to that shown in Fig. 3 (curve $P$ ), and their ultimate analyses are given in Table II. If 4660 represents the 'activity' of the specimen on 8 December, then only 22 , or less than $0.5 \%$, was due to strontium-all the rest represents excess yttrium. ${ }^{1}$

In passing, it may be mentioned that the half-life of $\mathrm{Y}^{90}$ was estimated as being $63.4 \mathrm{hr}$. (2.642 days). This value has been adopted in the present computations. It is close to an average of various estimates given to date by different authorities.

\section{An Experiment with other Algae}

Before attempting to interpret the results already described it is well to examine the behaviour of some other species of marine algae. How far, it may be asked, does the contrast found between Fucus serratus and Rhodymenia palmata reflect a constant difference between brown algae and red algae as a whole?

Experiment $f$ was set up on $\mathrm{I} 9$ and 20 November. A volume of $250 \mathrm{ml}$. of freshly collected sea water was treated with some of the 'active' solution received in September. From a burette successive fractions of $20 \mathrm{ml}$. were drawn off into boiling tubes. There were twelve of these altogether, ten designated by the letters $A$ to $\mathcal{F}$, and two held as a control. All the boiling tubes used had been well cleaned with strong chromate cleaning solution.

The tubes $\mathcal{F}_{A}$ to $\mathcal{F}_{J}$ contained pieces of different kinds of algae. All tubes were sampled after an interval of 3 days. The main particulars, both of the set-up and of the results, are given in Table III. The 'decay' curves are shown in Fig. 7.

${ }^{1}$ Absorption of some of the $\beta$-rays by the thin cellophane covering may have somewhat favoured the $\mathrm{Y}^{90}$ at the expense of the $\mathrm{Sr}$. 


\section{Table II. 'Decay' of 'Activated' Rhodymenia Frond (SPecimen $L$ )}

Two independent analyses at two counter positions. The 'activity' units for position I are reduced by a factor of 2.92 to make them very nearly comparable with the measurements for position 2. Further particulars as in Table I.

\begin{tabular}{|c|c|c|c|c|c|c|c|c|}
\hline \multirow[b]{2}{*}{ Date } & \multicolumn{4}{|c|}{ Position I $(\div 2.92)$} & \multicolumn{4}{|c|}{ Position 2} \\
\hline & Time & $\begin{array}{c}\text { (I) } \\
\text { Total } \\
\text { activity }\end{array}$ & $\begin{array}{c}\text { (2) } \\
\text { Part due } \\
\text { to } \mathrm{Sr} \\
\text { equilibrium } \\
\text { mixture }\end{array}$ & $\begin{array}{l}\text { (3) } \\
\text { Part due } \\
\text { to } \\
\text { excess } \\
Y^{90}\end{array}$ & Time & $\begin{array}{c}\text { (I) } \\
\text { Total } \\
\text { activity }\end{array}$ & $\begin{array}{c}\text { (2) } \\
\text { Part due } \\
\text { to } \mathrm{Sr} \\
\text { equilibrium } \\
\text { mixture }\end{array}$ & $\begin{array}{c}\text { (3) } \\
\text { Part } \\
\text { due to } \\
\text { excess } \\
Y^{90}\end{array}$ \\
\hline 8 Dec. & 4.54 & $4659 \cdot 3$ & $2 I \cdot 9$ & $4637 \cdot 4$ & 5.29 & $4682 \cdot 8$ & $23 \cdot 2$ & $4659 \cdot 6$ \\
\hline 9 & 5.50 & $3625 \cdot 7$ & $21 \cdot 8$ & $3603 \cdot 9$ & 6.55 & $3582 \cdot 4$ & $23 \cdot I$ & $3559 \cdot 3$ \\
\hline Io & $5 \cdot 50$ & $2808 \cdot 4$ & $2 \mathrm{I} \cdot 7$ & $2786 \cdot 7$ & 6.39 & $2776 \cdot 5$ & $23 \cdot 0$ & 2753.5 \\
\hline II & 3.48 & $2162 \cdot 3$ & $2 I \cdot 5$ & 2140.8 & 4.46 & $2179 \cdot 8$ & $22 \cdot 9$ & $2156 \cdot 9$ \\
\hline I3 & I 2.22 & $1367 \cdot 3$ & $2 \mathrm{I} \cdot 3$ & I346.0 & 3.5 & I3I 3.8 & $22 \cdot 6$ & $1291 \cdot 2$ \\
\hline I4 & I. 48 & I034.8 & $2 I \cdot 2$ & IOI3.6 & 2.55 & IOI0.6 & $22 \cdot 5$ & $988 \cdot I$ \\
\hline I5 & $\mathrm{I} 2.2 \mathrm{I}$ & $817 \cdot 5$ & $2 \mathrm{I} \cdot 07$ & $796 \cdot 44$ & I. 32 & $805 \cdot 6$ & $22 \cdot 4$ & $783 \cdot 2$ \\
\hline I6 & $6.4 \mathrm{I}$ & 588.08 & $20 \cdot 95$ & $567 \cdot 13$ & $\left\{\begin{array}{l}2.1 \text { I } \\
5.43\end{array}\right.$ & $\begin{array}{l}622 \cdot 8 \\
593 \cdot 9\end{array}$ & $22 \cdot 2$ & $\left\{\begin{array}{l}600 \cdot 6 \\
571 \cdot 7\end{array}\right.$ \\
\hline I7 & 2.48 & $478 \cdot 60$ & $20 \cdot 84$ & $457 \cdot 76$ & $\begin{array}{r}1.43 \\
1.30\end{array}$ & $\begin{array}{l}593.91 \\
487 \cdot 35\end{array}$ & $22 \cdot 12$ & $465 \cdot 23$ \\
\hline I8 & I2.I 5 & $383 \cdot 15$ & $20 \cdot 73$ & $362 \cdot 42$ & 1.26 & $378 \cdot 50$ & $22 \cdot 00$ & $356 \cdot 50$ \\
\hline 20 & I. 33 & $229 \cdot 30$ & $20 \cdot 52$ & $208 \cdot 79$ & II.56 & $234 \cdot 20$ & $2 I \cdot 78$ & 212.42 \\
\hline $2 I$ & I. 47 & $\mathrm{I} 8 \mathrm{I} \cdot 54$ & $20 \cdot 4 \mathrm{I}$ & I6I.I3 & $12.2 \mathrm{I}$ & I 84.48 & $2 I \cdot 66$ & 162.82 \\
\hline 22 & I. 45 & 142.53 & $20 \cdot 31$ & $122 \cdot 22$ & 12.36 & 146.83 & $2 I \cdot 55$ & 125.28 \\
\hline 23 & I. 47 & $\mathrm{II}_{4} \cdot 62$ & $20 \cdot 20$ & $94 \cdot 42$ & $12.3 \mathrm{I}$ & II 7.44 & $2 I \cdot 45$ & 95.99 \\
\hline 24 & I.39 & $95 \cdot 17$ & $20 \cdot 10$ & 75.07 & I 2.35 & $96 \cdot 46$ & $2 I \cdot 34$ & $75 \cdot 12$ \\
\hline 26 & 12.35 & 64.04 & 19.90 & $44 \cdot 14$ & II. 46 & 66.46 & $2 \mathrm{I} \cdot \mathrm{I}_{3}$ & $45 \cdot 33$ \\
\hline 28 & 2.2 & 44.97 & 19.71 & $25 \cdot 26$ & 12.29 & $45 \cdot 86$ & 20.92 & 24.94 \\
\hline 29 & I.59 & $39 \cdot 48$ & $19.6 \mathrm{I}$ & 19.87 & 12.36 & $40 \cdot 68$ & $20 \cdot 82$ & 19.86 \\
\hline 30 & 2.56 & $34 \cdot 4 \mathrm{I}$ & 19.52 & I 4.89 & I.I3 & $36 \cdot 92$ & $20 \cdot 71$ & I6.2I \\
\hline I7 Jan. & 6.8 & I6.97 & 18.00 & - & - & - & - & - \\
\hline I8 & I. 44 & I6.97 & I7.94 & - & I2.I8 & I6.89 & 19.05 & - \\
\hline I 8 & 6.38 & I6.95 & I7.92 & - & 5.13 & $17 \cdot 45$ & 19.03 & - \\
\hline
\end{tabular}

TABle III. The Results of Experiment $\mathcal{F}$

\section{Species}

Fucus serratus L.

F. serratus (in dark)

$F$. vesiculosus L.

$F$. vesiculosus var. evesicu-

losus Cotton (young growth)

Ascophyllum nodosum Le Jol

Laminaria digitata (L.)

Lamour.

Laminaria digitata (L.)

Lamour.

Chondrus crispus Stackh.

Gigartina stellata Batt.

Ulva lactuca $\mathrm{L}$.

Control I

Control 2
Final

Weight
Tube of weed Initial
no. (g.) 'activity'

'activity' Degree of in \% of strontium

f. I.74 36r (22. xi)

$\begin{array}{lll}\mathcal{F}_{B} & \mathrm{I} \cdot 74 & 36 \mathrm{I}(22 . \mathrm{xi}) \\ & \mathrm{I} \cdot 74 & 478(\mathbf{2 2} \times \mathrm{xi})\end{array}$

$\mathcal{F}_{D} \quad 3.4 \mathrm{I} \quad 326(22 . \mathrm{xi})$

$\begin{array}{lll}\mathscr{f}_{H} & 3.32 & 314(23 . x i)\end{array}$ control concentration

$\begin{array}{lll}23.03 & 39.5 & \text { Much } \\ 28.23 & 30.0 & \text { Much }\end{array}$

30.0

$20.46 \quad 23.4$

I5. I3 $34 \cdot 7$

$f_{G} \quad 5$.OI $242(22 . x i)$

$\mathrm{I} 5 \cdot 98 \quad 2 \mathrm{I} \cdot 6$

$48 \cdot 4 \mathrm{I}$

I4. I

$f_{J} \quad 6.29 \quad 286$ (23. xi)

I 8.55

I $4 \cdot 3$

$f_{E} \quad$ I.45 I296 (22. xi)

89.5

69.0

$\mathrm{I} \cdot 66$

$2 \cdot 20$

I. 16

$87 \cdot 5$

I00.0

-
Degree of yttrium absorption

Much

- Nearly all Little

All (or nearly all)

Very much

Some

All (or nearly all)

All (or nearly all)

All (or nearly all)

Little

Very little 

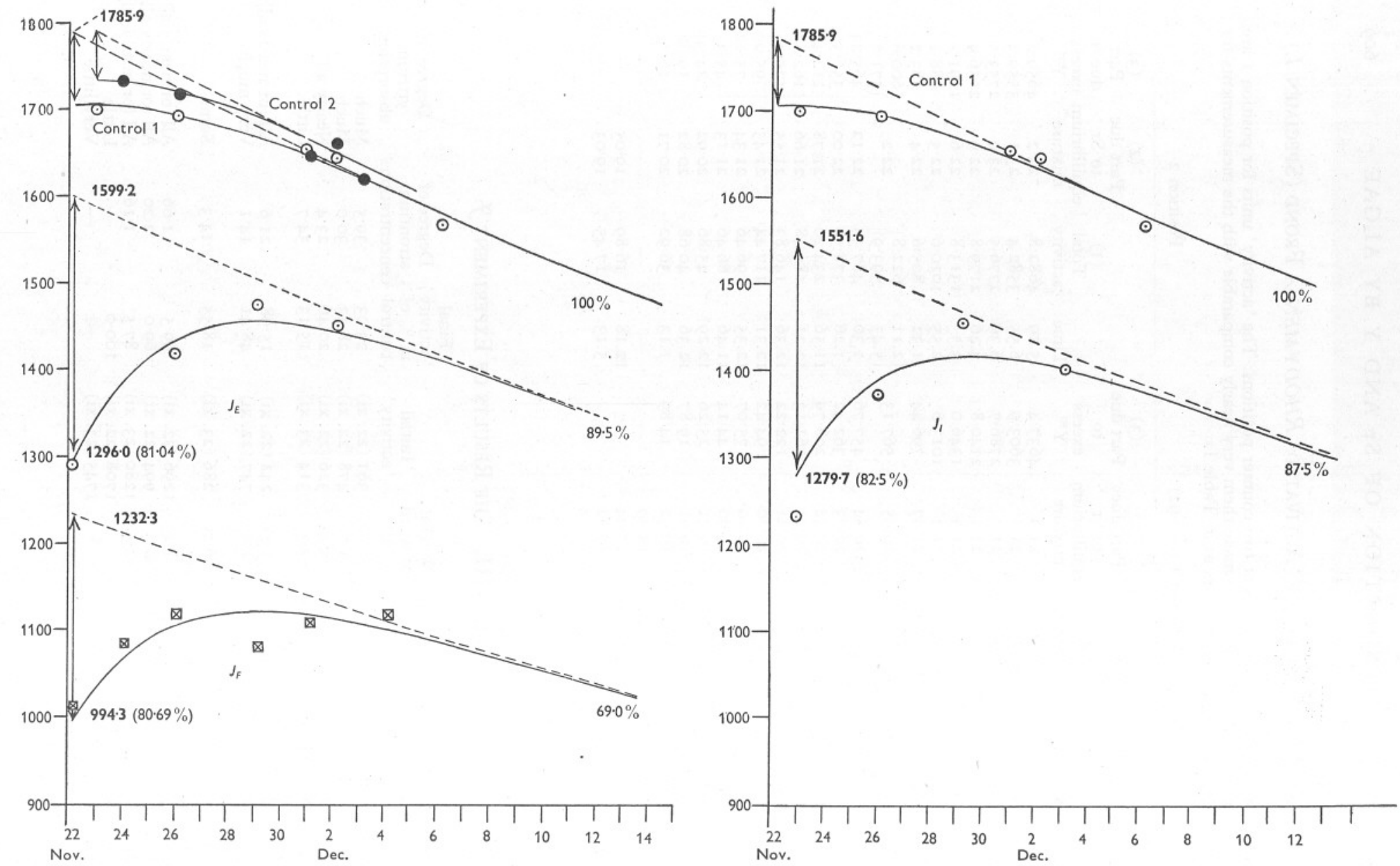

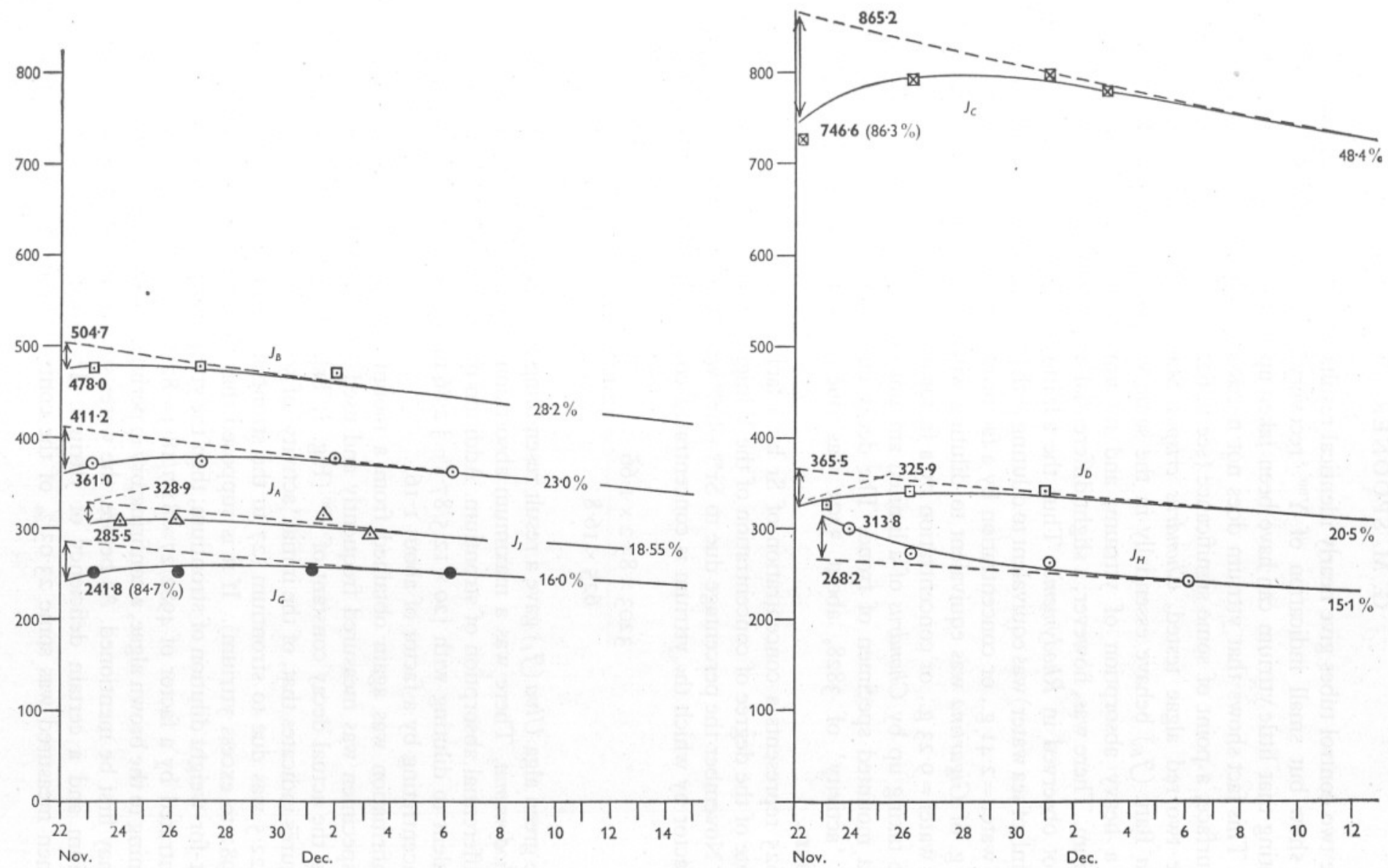

Fig. 7. Results of Exp. 7: 'decay' curves of specimens of 'activated' sea water which had contained pieces of various Algae, compared with a control of 'activated' sea water without additions. All tubes contained $20 \mathrm{ml}$. of sea water, and the weeds were added as follows:

$\mathcal{F}_{4}, \mathrm{I} \cdot 74 \mathrm{~g}$. of Fucus serratus; $\mathfrak{F}_{B}, \mathrm{I} \cdot 74 \mathrm{~g}$. of $F$. serratus; $\mathcal{F}_{C}, \mathrm{I} \cdot 55 \mathrm{~g}$. of Laminaria digitata; $\mathfrak{F}_{D}, 3 \cdot 4 \mathrm{I}$ g. of Fucus vesiculosus; $\mathfrak{F}_{E}$, I.45 g. of Chondrus crispus; $\mathscr{F}_{F}, 4.2 \mathrm{~g}$. of Gigartina stellata; $\mathfrak{F}_{G}, 5.01 \mathrm{~g}$. of Ascophyllum nodosum; $\mathfrak{F}_{H}, 3.32 \mathrm{~g}$. of Fucus vesiculosus var. evesiculosus; $\mathfrak{F}_{I}, 2 \cdot 54 \mathrm{~g}$. of Ulva lactuca; $\mathscr{F}_{J}, 6 \cdot 29 \mathrm{~g}$. of Laminaria digitata.

Final readings, critical in determining the relative equilibrium values, were made in March I949, and are not shown (the curves are thus fitted to more points than are shown in the Figure). Other details as in Figs. $\mathbf{I}$ and 2. 
The two control tubes give nearly identical results which can be combined. They show but small indication of $\mathrm{Y}^{90}$ 'recovery', particularly Control 2, indicating that little yttrium can have been taken up by the clean glass of the tubes. This fact shows that yttrium does not necessarily adsorb on any avail-able surface, a point of some significance (see p. 622).

The two red algae tested, Chondrus crispus Stackh. $\left(\mathcal{F}_{E}\right)$ and Gigartina stellata Batt. $\left(\mathcal{f}_{F}\right)$ behave essentially in the same way as Rhodymenia. They show a heavy absorption of yttrium, and no important concentration of strontium. There was, however, a slight differential uptake of strontium which was not observed in Rhodymenia. Thus the addition of $\mathrm{r} \cdot 45 \mathrm{~g}$. of Chondrus (to $20 \mathrm{ml}$. of sea water) was equivalent to diluting with $[20 \times 10.5 / 89.5=] 2.35 \mathrm{ml}$. of sea water $=2.4 \mathrm{I}$ g., or concentration by a factor of $\mathrm{I} \cdot 66$; while the addition of 4.2 g. of Gigartina was equivalent to diluting with $[20 \times 31 / 99=] 8.99 \mathrm{ml}$. of sea water $=9 \cdot 23 \mathrm{~g}$., or concentration by a factor of $2 \cdot 20$.

The taking up by Chondrus of a limited amount of strontium was verified from a mounted specimen of frond. The decay curve indicates that, of an initial 'activity' of 3828 , about 3203 was due to yttrium and 625 to strontium.

If 625 represents a concentration of $\mathrm{Sr}$ by a factor of $\mathrm{I} \cdot 66$, then a rough estimate of the degree of concentration of the Y might be obtained as follows. On 22 November the percentage due to $\mathrm{Sr}^{89}+\mathrm{Sr}^{90}$ was $83 \cdot 20$ and to $\mathrm{Y}^{90}$ I6.80. The factor by which the yttrium is concentrated could be regarded as

$$
\frac{3203 \times 83 \cdot 2 \times \mathrm{I} \cdot 66}{625 \times \mathrm{I} 6 \cdot 8}=42 \cdot \mathrm{I}
$$

The green alga Ulva $\left(\mathcal{F}_{I}\right)$ gave a result resembling that previously described for Rhodymenia. There was a maximum absorption of yttrium, and scarcely any differential absorption of strontium. Addition of $2.54 \mathrm{~g}$. of the frond was equivalent to diluting with $[20 \times \mathrm{I} 2.5 / 87.5=] 2.86 \mathrm{ml}$. of sea water $=2.93 \mathrm{~g}$., or concentrating by a factor of about I.I6.

Confirmation was again obtained from a mount of a piece of the weed. This specimen was measured frequently and used for the purpose of determining the actual decay constant of $\mathrm{Y}^{90}$ (Fig. 8, Table IV). Final analysis of the figures indicates that, of the initial 'activity' of 5009 (on 3 December) only some 22.5 was due to strontium ( 27 to the strontium 'equilibrium' mixture and 4982 to excess yttrium). If it is supposed that the 27 represents simple weight-for-weight dilution of strontium, then the yttrium appears to have been concentrated by a factor of $4982 / 27 \times 8 \mathrm{I} \cdot 7 / \mathrm{I} 8 \cdot 3=824$.

Coming to the brown algae, a confirmatory experiment with Fucus serratus L. $\left(\mathcal{F}_{A}\right)$ may first be mentioned. As before, the water showed a big deficiency of strontium and a certain deficiency of yttrium. The final 'activity' of the specimen measured was some $23.03 \%$ of the control. Thus the addition of 


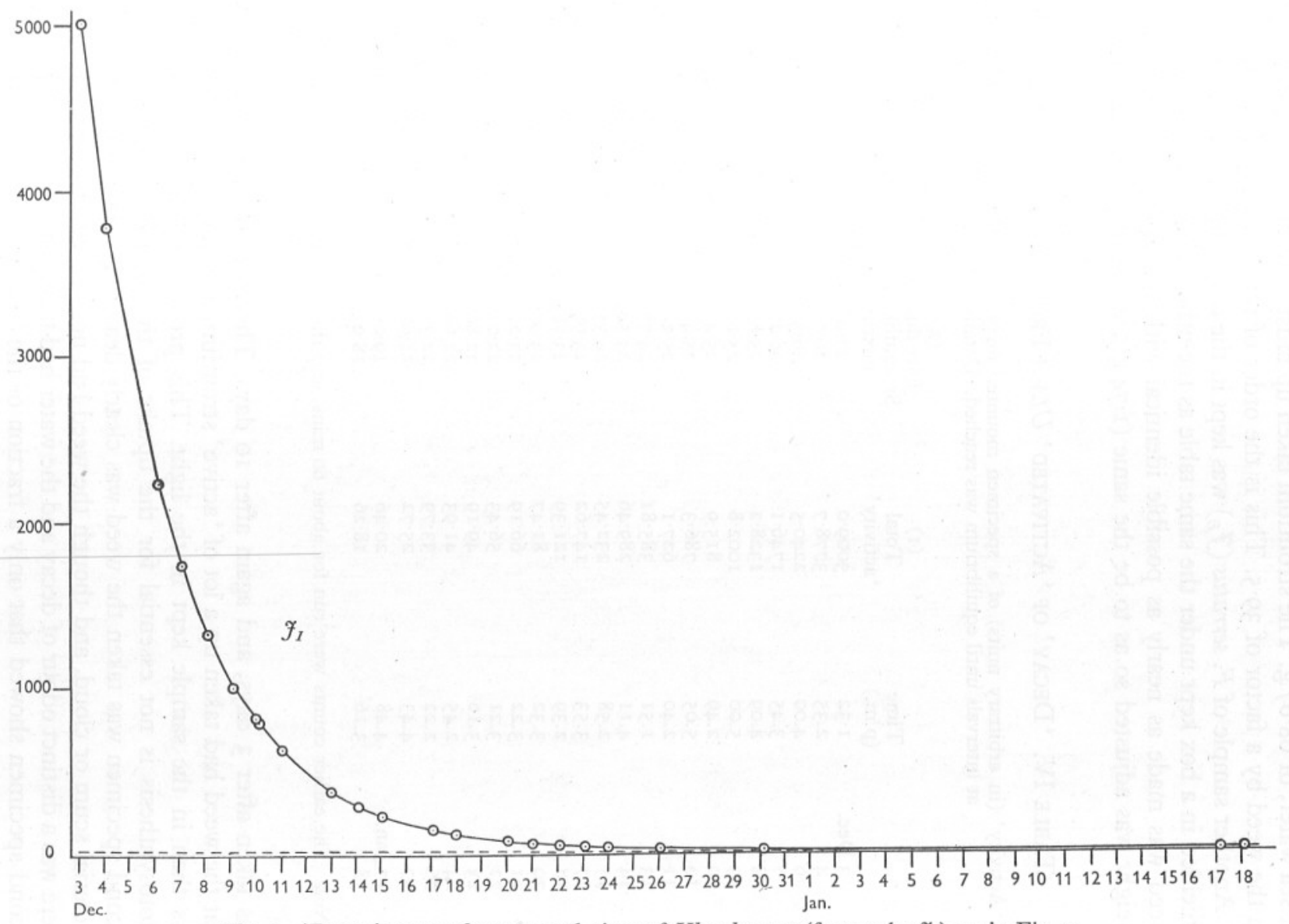

Fig. 8. 'Decay' curve of a mounted piece of Ulva lactuca (from tube $f_{I}$ ), as in Fig. 3 . 
I.74 g. of weed was equivalent to diluting with $20 \times 77 \cdot 0 / 23 \cdot 0=66 \cdot 87 \mathrm{ml}$. of sea water, or $68.67 \mathrm{~g}$. The strontium taken up must have been concentrated in the weed by a factor of 39.5 . This is the order of result already obtained.

Another sample of $F$. serratus $\left(\mathcal{F}_{B}\right)$ was kept in the dark, the tube being well shielded in a box kept under the same table as the other tubes. The sample of weed was made as nearly as possible identical with the other $\left(\mathcal{F}_{A}\right)$, and its weight was adjusted so as to be the same (I·74 g.). A specimen of the water

\section{Table IV. 'Decay' of ‘Activated' Ulva Frond (SPecimen $\mathcal{f}_{I}$ )}

'Activity' (in arbitrary units) of a specimen mounted on 3 December and measured at intervals until equilibrium was reached. Details as in Table I

\begin{tabular}{|c|c|c|c|c|}
\hline & $\begin{array}{l}\text { Time } \\
\text { (p.m.) }\end{array}$ & $\begin{array}{c}\text { (I) } \\
\text { Total } \\
\text { 'activity' }\end{array}$ & $\begin{array}{l}\text { (2) } \\
\text { Part due to } \\
\text { Sr equilibrium } \\
\text { mixture }\end{array}$ & $\begin{array}{l}\text { (3) } \\
\text { Part due to } \\
\text { excess } \mathrm{Y}^{90}\end{array}$ \\
\hline 3 Dec. & $I \cdot 32$ & $5009 \cdot 0$ & $27 \cdot 0$ & $4982 \cdot 0$ \\
\hline & 2.35 & $3778 \cdot 7$ & $26 \cdot 7$ & $3752 \cdot 0$ \\
\hline 6 & 4.00 & $2240 \cdot 5$ & $26 \cdot 3$ & $2214 \cdot 2$ \\
\hline 7 & 3.45 & I $746 \cdot \mathrm{I}$ & $26 \cdot I$ & $1720 \cdot 1$ \\
\hline 8 & 4.09 & $1328 \cdot 2$ & $25 \cdot 8$ & I 302.4 \\
\hline 9 & 5.00 & $1002 \cdot 8$ & 25.6 & $977 \cdot 2$ \\
\hline IO & 2.49 & 815.9 & 25.4 & 790.5 \\
\hline IO & 5.05 & $786 \cdot 3$ & $25 \cdot 4$ & $760 \cdot 9$ \\
\hline II & 2.40 & $627 \cdot \mathrm{I}$ & $25 \cdot 2$ & $601 \cdot 8$ \\
\hline I3 & I.5I & $385 \cdot 8 \mathrm{I}$ & $24 \cdot 77$ & $36 r \cdot 04$ \\
\hline I4 & 4.II & $289 \cdot 46$ & $24 \cdot 54$ & 264.92 \\
\hline I5 & 2.58 & $232 \cdot 45$ & $24: 35$ & $208 \cdot 10$ \\
\hline 17 & 3.53 & $147 \cdot 62$ & 23.96 & 123.66 \\
\hline I8 & 2.39 & I $21 \cdot 39$ & $23 \cdot 78$ & $97 \cdot 6 \mathrm{I}$ \\
\hline 20 & $3 \cdot 32$ & $8 \mathrm{r} \cdot 47$ & 23.40 & 58.07 \\
\hline $2 I$ & 3.22 & $66 \cdot 19$ & $23 \cdot 22$ & 42.97 \\
\hline 22 & 3.21 & 56.43 & 23.03 & $33 \cdot 40$ \\
\hline 23 & 3.10 & $49 \cdot 19$ & $22 \cdot 86$ & $26 \cdot 33$ \\
\hline 24 & 2.45 & $4 \mathrm{I} \cdot 93$ & $22 \cdot 68$ & 19.25 \\
\hline 26 & 2.22 & 33.79 & $22 \cdot 35$ & II. 44 \\
\hline 30 & 4.43 & $25 \cdot 72$ & $2 I \cdot 66$ & 4.06 \\
\hline I7 Jan. & 4.48 & 20.46 & 19.05 & - \\
\hline & 3.16 & I $8 \cdot 26$ & I8.93 & 一 \\
\hline
\end{tabular}

Note. The earlier counts were run for about $60 \mathrm{mins}$. and the later from 60 to $90 \mathrm{~min}$.

was taken after 3 days, and again after Io days. The first specimen showed that the weed had taken up a lot of 'active' strontium as usual, though rather less than in the sample kept in the light. This proved at least that active photosynthesis is not essential for the uptake of the strontium. When the second specimen was taken the weed was clearly dead. Though there was no bacterial scum or cloud, and though the weed had not started to disintegrate, there was a distinct odour of decay and the water had turned bluish green. The second specimen showed that only a fraction of the 'active' Sr had returned to the sea water, the concentration factor having fallen from $30 \cdot 0$ to $22 \cdot 5$. Thus $75 \%$ of the amount originally taken up remained in the weed. Exactly the 
same fraction also remained in the sample $\mathcal{F}_{A}$ when this was killed by heating, the concentration factor falling from $39 \cdot 47$ to $29 \cdot 83$.

Two other tubes were given to $F$. vesiculosus $\mathrm{L}$. One sample, of $3.4 \mathrm{I}$ g., was of a well-grown typical piece of frond with a number of vesicles $\left(\mathfrak{f}_{D}\right)$; the other, of $3.32 \mathrm{~g}$., was of young fronds of a non-vesicled form (var. evesiculosus Cotton), growing in the upper part of the shore below the Laboratory $\left(\mathcal{f}_{H}\right)$.

Both took up a lot of strontium, especially the non-vesicled form. The addition of the $3.32 \mathrm{~g}$. of this weed was equivalent to dilution with

$$
20 \times 84 \cdot 87 / I_{5} \cdot I_{3}=\text { II } 2 \cdot 19 \mathrm{ml} \text {. of sea water }=I I 5 \cdot 22 \mathrm{~g} .
$$

The factor for the concentration of strontium is thus 34.7 . For the typical sample $\left(\mathcal{F}_{D}\right)$ the concentration factor is 23.4 .

An unexpected difference between these two samples is seen in their relation to yttrium. The typical sample $\left(\mathcal{F}_{D}\right)$ appears to have taken up all, or nearly all, the available yttrium, a very marked recovery being shown by the specimen of the water. Not so, however, with the var. evesiculosus sample $\left(\mathscr{f}_{H}\right)$. The specimen of the water surrounding it was not deficient in yttrium in any way: within the limits of accuracy of the 'decay' curve it was either in equilibrium at the start, or, more probably, had a small excess of yttrium, as distinctly shown in Fig. $7\left(f_{H}\right)$. The last alternative is proved to be correct, as two specimens of the actual weed from tube $\mathcal{F}_{H}$ were mounted and their 'decay' characteristics observed. The 'decay' curve of both these specimens shows evident yttrium recovery at the start (the inverse, of course, to the behaviour of the water). The extent of recovery indicates that the degree of yttrium concentration in the weed, if indeed appreciable, was far less than that of strontium. Among the algae tested $F$. vesiculosus var. evesiculosus was the only one to behave in this way.

Ascophyllum nodosum Le Jol absorbs much strontium, concentrating it to the extent of some $2 \mathrm{I}$ times, and apparently much yttrium.

There remain the two samples of Laminaria digitata (L.) Lamour. One $\left(\mathcal{F}_{C}\right)$ consisted of a piece of frond, $\mathrm{I} \cdot 55 \mathrm{~g}$. in weight; the other $\left(\mathcal{F}_{J}\right)$ of a large piece of the base of the frond with some stipe of which a length, which became desiccated, protruded from the water. The submerged part of the last weighed $6 \cdot 29 \mathrm{~g}$.

The results of these two samples essentially agree. Much $\mathrm{Y}^{90}$ appears to have been taken up by the Laminaria, best demonstrated by the 'recovery' in the $\mathfrak{f}_{C}$ curve. At the same time a fair amount of 'active' $\mathrm{Sr}$ was also taken up, the concentration factor for $\mathcal{F}_{C}$ being I $4 . \mathrm{I}$ and for $\mathcal{F}_{J} \mathrm{I} 4 \cdot 3$. The two values derived from such different weights of weed are in excellent agreement.

Thus all the four brown algae tested agreed in the general property of concentrating 'active' strontium, the effectiveness in this respect being shown in the following sequence: Fucus serratus, F. vesiculosus, Ascophyllum nodosum, and Laminaria digitata. 


\section{INTERPRETATION IN TERMS OF IONIC EXCHANGE}

How is this capacity for absorbing the 'active' strontium or yttrium to be interpreted or visualized? At the risk of over-simplification three main possibilities have to be considered: (i) adsorption, (ii) ionic exchange, (iii) extraction.

The capacity for metallic ions to become adsorbed on surfaces is well known. In sea water, elements present in very small concentrations may readily do this, as, for example, Harvey (1937, I949) finds with iron and manganese. Mud particles, faecal pellets, and parts of organisms of all sizes, may at times provide suitable surfaces. The extent to which any element will get adsorbed will depend on the degree of previous saturation of the surface with the element. This process, it may be noted, involves active removal of the element as a whole from solution, including any radioactive isotopes which may have been added to it; and might easily go to the extent of removing all except an insignificant trace. The marine chemist has acquired the habit when dealing with an element of low concentration, of enquiring how much of it may be getting adsorbed on the apparatus with which the water is brought in contact.

The phenomenon of ionic exchange is quite different. The concentration of a given element inside an organism may not be the same as that in the water outside. For example, a much higher concentration may be maintained by the organism, which does work against osmotic forces. But, whatever the relative concentration in the organism, there may be free exchange between the ions of the outside water and those of the internal fluids. If some of the ions in the water outside are labelled in some way, after an interval these will be found distributed inside the organism as well as outside. This will happen when a radioactive isotope is introduced. At first all its ions will be outside; but after an interval these will become generally distributed at random throughout the population of the particular ion. So they will be most numerous where that element is concentrated, and vice versa. If the element is concentrated in the organism, say an alga, then the radioactive ions will be found to enter the alga, and the extent to which they aggregate in the weed will provide an exact measure of the relative concentration of the element in the weed. There is, therefore, no passage of the element as a whole into the weed, and the respective concentrations in weed and water remain unaltered (assuming the amount of active isotope is negligible). There is simply a random interchange of ions amongst the existing population. Ion exchange is only liable to reduce the amount of 'active' isotope in the external medium to a negligible quantity if there is very great difference between the concentration inside and outside the weed, and this will not frequently occur. Increasing the weight of the weed added to a given volume of water becomes increasingly ineffective: the effect is in no way additive. 
The third possibility has features in common with both the preceding. Extraction resembles adsorption in that it involves removal by the organism of the element as a whole, but differs in that the ions pass into the organism where they may be 'locked up'-as, for example, calcium in skeletal tissue or mollusc shells. At the same time extraction may develop as a special case of ionic exchange when ions are progressively removed from circulation inside the organism so that fewer return to the outside solution than are taken from it. As in simple ionic exchange, passage of 'active' ions into, for example, an alga indicates that the weed has a higher concentration of the element inside. it, but where extraction is going on there is active uptake of the element as a whole, which may proceed steadily until all the element is removed from solution. The attainment of an equilibrium is less probable, and, within limits, the effect of increasing the amount of weed is likely to be additive.

With strontium which exists in comparative plenty in sea water (about $0.04 \%$ of total salts, $\left.=\mathrm{I} 4 \mathrm{~g} . / \mathrm{m}^{3}\right)$, it is assumed that the chance of uptake by adsorption is negligible. First, all surfaces will already be saturated with the quite small quantities which may be taken up in this way. Secondly, the proportion of strontium which may be found adsorbed at any one moment is likely to be small, or very small, compared with that of ions free in solution; because of which the loss of radioactive ions by ionic exchange with surfaces already saturated may be supposed to be negligible.

As far as the red and brown algae considered here are concerned, it seems almost certain that progressive extraction can be ruled out. The consideration is likely to arise only with calcareous algae, amongst which there might be possibilities of precipitation of strontium along with the calcium carbonate. In the results obtained above it seems that the main effects occurred quickly, and the loss of 'activity' certainly did not vary directly with the weight of the weed.

Straightforward ionic exchange seems the only possible interpretation, which is positively indicated by the sort of effects obtained when the weight of the weed is increased. The two samples of L. digitata $\left(\mathcal{F}_{C}\right.$ and $\left.\mathcal{F}_{J}\right)$ are striking in this respect from two very dissimilar weights, I.55 and 6.29 g., and identical estimate of the degree of concentration of the strontium is obtained. As a plausible working hypothesis, therefore, the uptake of strontium is regarded as essentially a matter of ionic exchange. If, as happens, the radioactive $\mathrm{Sr}$ ions disappear from the water into the weed it is because the weed all along contains a heavier concentration of strontium than the water. Moreover, the measure of the degree of concentration of the 'active' Sr ions in the weed (as given in Table III on a weight for weight basis) is a measure of the concentration of the weed's normal strontium content. It is concluded, therefore, that Fucus serratus has about 40 times as much strontium as sea water ${ }^{1}$, Laminaria digitata about I4 times, while no or very little concentration or even positive exclusion is shown by three red algae and Ulva lactuca.

\footnotetext{
${ }^{1}$ There is now direct support for this conclusion: see p. 625 .
} 
The matter is rather different for yttrium. This element has been observed in sea water (see the chapter on the minor constituents of sea water in Harvey, I945, pp. 3I-42), and it appears to be one of many whose concentration is of the order of I mg. $/ \mathrm{m}^{3}$. It is likely, therefore, that adsorbant surfaces are far from saturated with it. Experience has shown that it quite readily adsorbs on unclean glass, from which it can only be finally removed by strong acid. Uptake by adsorption may therefore play a prominent part in the exchanges of this element, and special technique may be necessary to distinguish between adsorption and ionic exchange. This problem is further discussed below.

\section{EXPERIMENTS With CULtures of Unicellular AlgaE}

Certain preliminary experiments with algal cultures have not yet been developed on an adequate quantitative basis, but some qualitative results may be placed on record at this stage.

A portion of a culture was treated with some 'active' solution. It was allowed to stand until the organisms in the culture had aggregated at the bottom, or near surface, of the liquid. A drop containing the thickest aggregate obtainable of the organism was then withdrawn and compared with another drop from the main volume of the liquid, or from its clearest part. By this means it was hoped to detect differential absorption by the organisms in question, although dense aggregations were usually difficult to obtain and impossible to measure accurately in terms of weight or volume. As before, sample drops consisted of 0.05 c.c.

Chlorella (Exp. M). About 25 c.c. of a culture of Chlorella, reproducing at a slow rate, was treated to the extent of giving it an 'activity' of about 950 per 0.05 c.c. (measured from the first stage of the M.R.C. Castle). After standing for a day or two the Chlorella cells had tended to aggregate in a green ring at the bottom of the flask. A number of specimen drops were taken from this flask. All showed appreciable yttrium recovery, indicating that the glass wall of the vessel had adsorbed some, but by no means all, of the yttrium. The greatest deficiency of yttrium was each time shown by those drops taken close to the bottom (i.e. against the glass) away from the alga deposit. Drops taken from the bottom to include some of the Chlorella aggregate, which was dense enough to give a distinct greenish opacity to the evaporated drops, consistently showed a 5-10\% higher 'activity' than other drops. It would seem that the Chorella definitely concentrated some of the strontium, but since the weight of alga involved was not ascertained, no estimate of the degree of concentration can be given.

Chlamydomonas. A series of tubes containing a Chlamydomonas culture was used to test lethal doses. From one of the relatively more weakly activated tubes, in which a flourishing colony of the alga had grown and aggregated at the surface, two strongly contrasting drops were obtained-one densely green, 
and the other clear to the naked eye (Exp. Ch). Rather heavy yttrium recovery took place in both drops, but more in the control than in the drop containing the Chlamydomonas. This indicates that some of the yttrium lost from solution had been taken up by the Chlamydomonas. There was an appreciably higher 'activity' remaining in the drop containing the alga, some $6 \%$ greater than the 'activity' of the clear drop, indicating that the Chlamydomonas had also concentrated strontium to some extent.

Nitzschia. On ro November a fairly dense culture of this diatom was 'activated' with 'active solution $A$ ' (The September solution diluted $\times$ I4). This was done in the following way. 50 c.c. of fresh sea water was 'activated' with 0.5 c.c. of solution $A$. This was exactly halved, one half being set aside as control (flask $Y$ ). To the other half, 25.25 c.c., were added Io c.c. of Nitzschia culture and a further 0.I c.c. of solution $A$. This mixture, comprising 35.35 c.c. (labelled flask $X$ ), was stood near a fluorescent source of light.

In the course of hours the diatoms formed a layer on the bottom of the flask, and the main volume of the medium grew steadily clearer. Samples were first taken on I3 November and again on I8 November. The results of the two samples are similar, and very striking (Figs. 9-10).

The curves in Figs. 9-Io show measurements of three drops from the control flask $-Y_{1}$, Io November; $Y_{2}$, I 3 November; $Y_{3}$, I 8 November. They show also measurements of two drops taken from the top of the liquid in the diatom flask, and containing very few, if any, diatoms $-X_{2}, 13$ November; $X_{3}$, I8 November. These drops all behave much alike: their 'activity', within experimental limits, became identical; though at the start there were definitely more signs of yttrium recovery in the $X$ specimens.

In contrast to these, there were three drops taken from the bottom of the flask in an attempt to pick up as much Nitzschia deposit as possible- $X_{1}$, I3 November; $X_{4}$ and $X_{5}$, I8 November. In these the liquid looked very brown, though the actual proportional volume of diatom cannot have been great-perhaps, at a guess, one-fiftieth of the 0.05 c.c. drop.

The 'activity' of these drops was great at first-over twice that of the controls, or drops from the top of the same flask.

But 'decay' proceeded fairly rapidly, until in 3 weeks it had virtually fallen to that of the other specimens. It is plainly seen that all the excess 'activity' at the start had been due to excess $\mathrm{Y}^{90}$ in the Nitzschia-containing drops. (The converse, deficiency of $\mathrm{Y}^{90}$, is quite distinct in the clear $X$ drops, as indicated above.)

Nitzschia cells, therefore, are capable of taking up yttrium very heavily.

It may be supposed that this phenomenon is due to the adsorption of yttrium on the diatom. These minute attenuated cells with porous or pitted surfaces present an enormous surface area.

Experimental evidence for this view is provided by the test of killing the 
culture. On 23 November the whole flask was heated to nearly boiling point and the cells completely killed. Similar specimens as before were taken on 25 November after settling had taken place. But the results were exactly as before $-X_{6}$, from the top of the flask, gave similar measurements to $X_{2}$ and $X_{3}$, and $X_{7}$, with bottom deposit, gave as high a reading as before $\left(X_{1}, X_{4}\right.$, $\left.X_{5}\right)$. No yttrium had come out of the dead cells: it is certain that at least

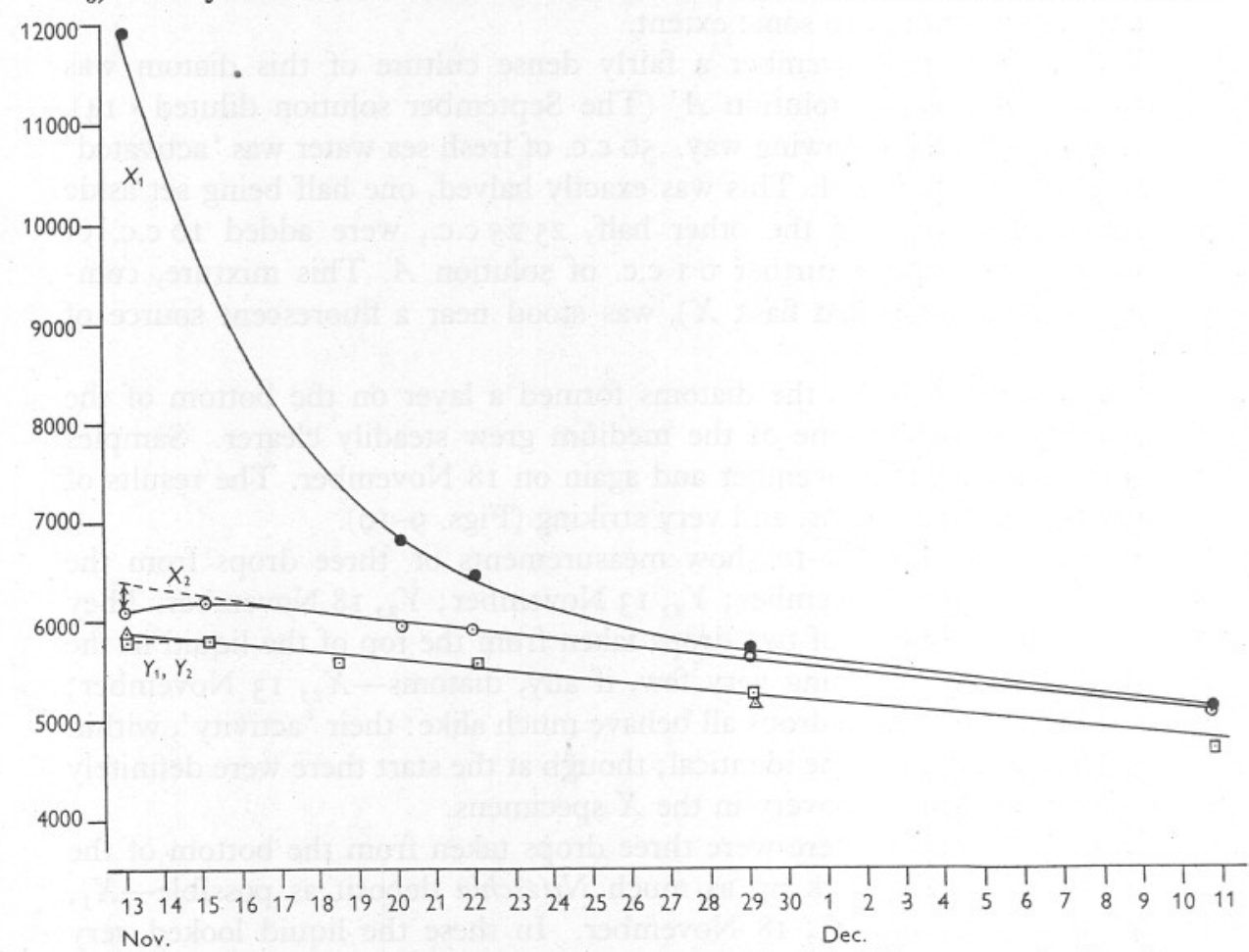

Fig. 9. 'Decay' curve of a specimen of water rich in Nitzschia $\left(X_{1}\right)$, compared with culture. water more or less free from Nitzschia $\left(X_{2}\right)$ and with a sea-water control $\left(Y_{2}\right)$.

a substantial part would have returned to solution (not necessarily all-cf. Fucus killed in the same way) had the yttrium been held by simple ionic exchange.

This result suggests that diatoms as a whole, as well as other organisms such as sponges, are potential takers up of yttrium and other metals related to the rare earths. This possibility certainly needs pursuing further.

\section{Discussion}

The experiments described above have been essentially exploratory, and any conclusions suggested by them must, in the main, be provisional, awaiting confirmation from the many further lines of experimentation which suggest themselves. 
It is, however, clear enough that at least some of the commoner brown algae have a considerable capacity for taking up 'active' strontium ions from the water around them. The provisional explanation is that the weeds have, in their normal make-up, a relatively high content of strontium, and that the 'active' strontium ions enter the alga by simple ionic exchange. It is thus

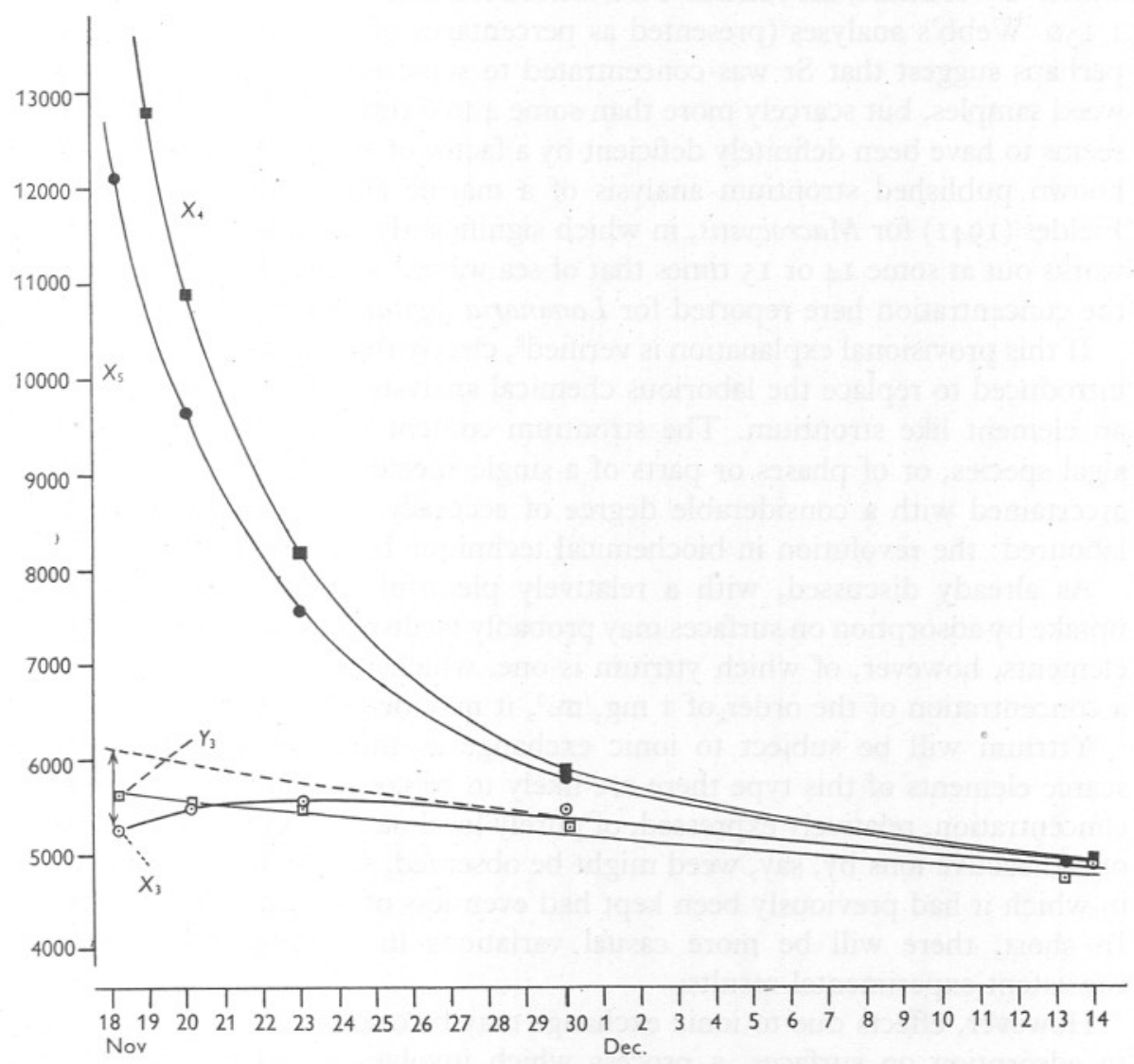

Fig. Io. Repetition of results with Nitzschia shown in Fig. 9. $X_{4}$ and $X_{5}$ are specimens of culture water from the bottom of the flask, rich in Nitzschia (cf. $\left.X_{1}\right) . X_{3}$ is a specimen of the clear culture water from the top of the flask (cf. $X_{2}$ ). $Y_{3}$ is a second specimen from the control flask.

supposed that there is no actual change in concentration of total strontium either in the weed or in the water. This is a straightforward chemical proposition, susceptible of test by direct chemical analysis. If it were not for the unusual difficulties in estimating strontium, owing to its very close affinity to calcium (see Webb, I938), adequate information on strontium-content of different algae might have been available long ago. As it is, the scanty available 
data are suggestive. From Webb's (1937) spectrographically derived data, Fucus serratus receptacles and Sacchorhiza bulbosa stipe are seen to have had a high $\mathrm{Sr} / \mathrm{Ca}$ content of about I/IO, three times as great as in sea water. These were the only two out of 23 analysed tissues of marine organisms (mostly animal) in which the $\mathrm{Sr} / \mathrm{Ca}$ ratio was appreciably greater than that of sea water. By contrast, the ratio in Ulva lactuca frond is found to have been about I/I50. Webb's analyses (presented as percentages of total cations in the ash) perhaps suggest that $\mathrm{Sr}$ was concentrated to some extent in the two brownweed samples, but scarcely more than some 4 to 6 times; while in Ulva the Sr seems to have been definitely deficient by a factor of at least $\frac{1}{2}$. The only other known published strontium analysis of a marine alga is that by Wilson \& Fieldes (I94I) for Macrocystis, in which significantly enough, the figure given works out at some I4 or I5 times that of sea water, ${ }^{1}$ a value which agrees with the concentration here reported for Laminaria digitata (Table III, p. 609).

If this provisional explanation is verified ${ }^{2}$, clearly the tracer technique can be introduced to replace the laborious chemical analysis otherwise involved with an element like strontium. The strontium content of dozens of samples of algal species, or of phases or parts of a single species, could be quite rapidly ascertained with a considerable degree of accuracy. This point need not be laboured: the revolution in biochemical technique has already set in.

As already discussed, with a relatively plentiful element like strontium, uptake by adsorption on surfaces may probably be disregarded. With numerous elements, however, of which yttrium is one, which are present in the sea in a concentration of the order of $\mathrm{I} \mathrm{mg./m.} .^{3}$, it may be otherwise.

Yttrium will be subject to ionic exchange as much as strontium. With scarce elements of this type there are likely to be considerable fluctuations in concentration, relatively expressed, of purely local nature. Quite heavy uptake of radioactive ions by, say, weed might be observed, simply because the water in which it had previously been kept had even less of the element than usual. In short, there will be more casual variations in concentration, and less consistent experimental results.

However, effects due to ionic exchange may be overshadowed by those due to adsorption on surfaces, a process which involves actual removal of the element from the water. The tendency for glass surfaces, particularly if not well cleaned, to adsorb yttrium is easily demonstrated. It is likely that the observed affinity of Nitzschia for yttrium (p. 6ra) is the result of adsorption on the surface of this diatom. Perhaps, too, the marked concentration of yttrium by the three red algae and Ulva might be purely a matter of adsorption on a surface: the almost complete removal of 'active' yttrium from solution by these weeds, which would otherwise imply an enormous concentration in the

\footnotetext{
1 Wilson \& Fieldes give values for parts per million of air-dried weed. It is assumed that air-dried weed is one-fifth the wet weight, and wet weight is compared directly with sea water.

${ }^{2}$ See Postcript, p. 624.
} 
weed compared with the sea water, suggest this explanation. But other considerations must be taken into account before a decision is made.

First, yttrium is not automatically adsorbed on to all surfaces. If glass is well cleaned with strong cleaning solution, there is very little yttrium uptake (Fig. 2(s), Fig. 5(w)). Secondly, the brown algae did not take it up anything like to the same degree as the red algae, and that, indeed, Fuscus vesiculosus var. evesiculosus took up very little. Though it is always possible that the yttrium loss on the glass of the vessel is variable and difficult to allow for exactly, the uptake by brown algae also seems variable and not readily predictable. It is possible therefore that uptake of $\mathrm{Y}^{90}$ in the brown algae is chiefly a matter of ionic exchange, while in the red algae and Ulva surface adsorption is predominant, and in Nitzschia adsorption virtually the sole cause. Further experiments are necessary to clear this matter up.

Of all elements, yttrium is one which has a minimum of biological significance: It plays no special part, as far as is known, or can be visualized, in the chemical exchanges of animals and plants. What purpose, therefore, is served in putting the observations on this element on record? In answer the following points may be brought to notice.

(i) However unimportant yttrium itself may be, its properties and behaviour are probably typical of a number of elements which occur very sparingly in the sea, and of which some are of proved biological importance. Facts derived from yttrium may prove equally applicable to iron, manganese, cobalt, etc., particularly with regard to adsorption phenomena.

(ii) Opportunity has been taken, while yttrium happened to be available for study, of developing technique which can be readily adapted to other elements. Not the least interesting point is that a good deal of information, partly quantitative, can be secured from an element which is (a) present in minute quantities, and $(b)$ not deliberately chemically separated. Yttrium is not easily obtained in pure chemical form, free from the related 'rare earth' elements, etc.; yet, when $\mathrm{Y}^{90}$ occurs as a daughter product of $\mathrm{Sr}^{90}$, it is pure and free from contamination of other elements which have similar chemical properties. (Its parent and daughter products are both in different columns of the periodic table.) The technique of using daughter isotopes as tracers opens up interesting possibilities.

(iii) It may be a matter of interest when a biological experiment proves capable, unexpectedly, of making a contribution to pure chemistry or physics. The discovery that some red algae and Ulva were able to concentrate $\mathrm{Y}^{90}$ at the expense of its parent, $\mathrm{Sr}^{90}$, enabled specimens to be prepared from which it is possible to make an apparently accurate estimate of the half-life of $\mathrm{Y}^{90}$. The attempt made by the present writer could no doubt easily be improved on by the same technique, yet it appears to be as reliable as any made hitherto, judging by the small margin of error which the figures obtained seem to allow. 


\section{Postscript}

Since the above was written the result has become known of an estimate of the strontium content of a sample of Fucus serratus ash, determined by the Analytical Group Chemistry Division of A.E.R.E. The ash was prepared at Plymouth by Mr F. A. J. Armstrong from a known weight of weed, and the $\mathrm{Sr}$ determination at A.E.R.E. made, after various difficulties had been overcome, by the technique of flame spectrometry.

The strontium content was reported as $0.9 \%$ of the ash, the ash originally representing $5.26 \%$ of the wet weed. The weed therefore contained $0.04734 \%$ of $\mathrm{Sr}$, as compared with the 0.00135 to $0.00140 \%$ believed to be characteristic of sea water. This difference represents a concentration of $\mathrm{Sr}$ in the weed by a factor of 34 or 35, and is in excellent agreement with the values derived above for Fucus serratus, supporting both the assumption that $\mathrm{Sr}$ is concentrated in this and other brown algae, and the validity of employing the tracer technique to provide quantitative assessments of the degree of this concentration.

\section{SUMMARY}

Certain marine algae were treated with sea water containing carrier-free radioactive strontium (mixture of $\mathrm{Sr}^{89}$ and $\mathrm{Sr}^{90}$ ), to test whether these ions were taken up by the weeds.

At the same time the behaviour of radioactive yttrium $\left(\mathrm{Y}^{90}\right)$, which occurred as a short-lived daughter-product of $\mathrm{Sr}^{90}$, was investigated by the expedient of studying the 'decay' characteristics of specimens of water and weed. Promising possibilities of this technique, by which an isotope is made available for study by applying its parent substance, are pointed out.

Radioactive strontium is extracted from sea water by the brown sea-weeds, in particular by Fucus serratus.

It is held that this effect is simply a result of ionic exchange, and that the algae regularly contain many times as much strontium in their cell fluids as exists in sea water.

On the ionic exchange hypothesis, it appears that Fucus serratus has about 40 times as much strontium as sea water, F. vesiculosus about 30, Ascophyllum nodosum about 20 , and Laminaria digitata about I4.

By contrast, red algae and green algae such as Ulva extract 'active' strontium only to a small or negligible extent. On the above hypothesis, in Gigartina the strontium is concentrated by a factor of about 2, while in Rhodymenia it may be less than in the sea.

Radioactive yttrium is heavily taken up by the red algae (Rhodymenia, Gigartina, Chondrus) and by the green alga Ulva, even to the extent of depleting the water of this element, or very nearly so.

The yttrium, however, is not usually heavily taken up by the brown algae, 
and may (as with a sample of Fucus vesiculosus var. evesiculosus) be taken up only to quite a small degree.

The diatom Nitzschia takes up 'active' yttrium very heavily.

The extraction of yttrium appears to be a matter partly of ionic exchange and partly of adsorption on surfaces. It is suggested that both processes may be important with red algae, the former primarily with brown algae, and the latter primarily with Nitzschia.

From the 'decay' characteristics of mounted pieces of frond of the red algae and Ulva, estimates of the true half-life of $\mathrm{Y}^{90}$ were made. The value derived is 63.4 hours (or 2.642 days).

\section{REFERENCES}

Harvey, H. W., 1937. The supply of iron to diatoms. Fourn. Mar. Biol. Assoc., Vol. 22, pp. 205-19.

- 1945. Recent Advances in the Chemistry and Biology of Sea Water, I64 pp. Cambridge.

- 1949. On manganese in sea and fresh waters. Fourn. Mar. Biol. Assoc., Vol. 28, pp. I55-64.

HoAg, J. Barton, revised by KorfF, S. A., 1948. Electron and Nuclear Physics, 522 pp. New York.

KaMEN, M. D., I948. Radioactive Tracers in Biology, 28I pp. New York.

LEA, D. E., I946. Actions of Radiations on Living Cells, 402 pp. Cambridge.

Pollard, E. \& Davidson, W. L., I942. Applied Nuclear Physics, 249 pp. New York.

SEABorg, G. T., I944. Table of isotopes. Rev. Modern Physics, Vol. I6, pp. I-32.

SMYTH, H. D., I945. A general account of the development of methods of using atomic energy for military purposes under the auspices of the United States government, I940-I945. Government of U.S.A. white paper (reprinted by H.M. Stationery Office, London).

WeBB, D. A., I937. Studies on the ultimate composition of biological material. Pt II : Spectrographic analyses of marine invertebrates, with special reference to the chemical composition of their environment. Sci. Proc. Roy. Dublin Soc., Vol. 2I, pp. 505-39.

WeBB, D. A., I938. Strontium in sea water and its effect on calcium determinations. Nature, Vol. I42, p. 51.

WILsON, S. H. \& FIELDES, M., I94I. Studies in spectrographic analysis. II. Minor elements in a sea-weed (Macrocystis pyrifera). New Zealand fourn. Sci. Techn., Vol. 23, No. 2B, pp. 47B-48B. 